\begin{tabular}{|l|l|}
\hline & $\begin{array}{l}\text { Gomez-Mancilla, Baltazar; Novartis Institutes for BioMedical Research, } \\
\text { Translational Medicine }\end{array}$ \\
\hline Keywords: & $\begin{array}{l}\text { Parkinson's disease, levodopa (L-dopa), nicotinic acetylcholine receptor } \\
\text { agonist (nAChR) a7, AQW051, dyskinesias }\end{array}$ \\
\hline
\end{tabular}
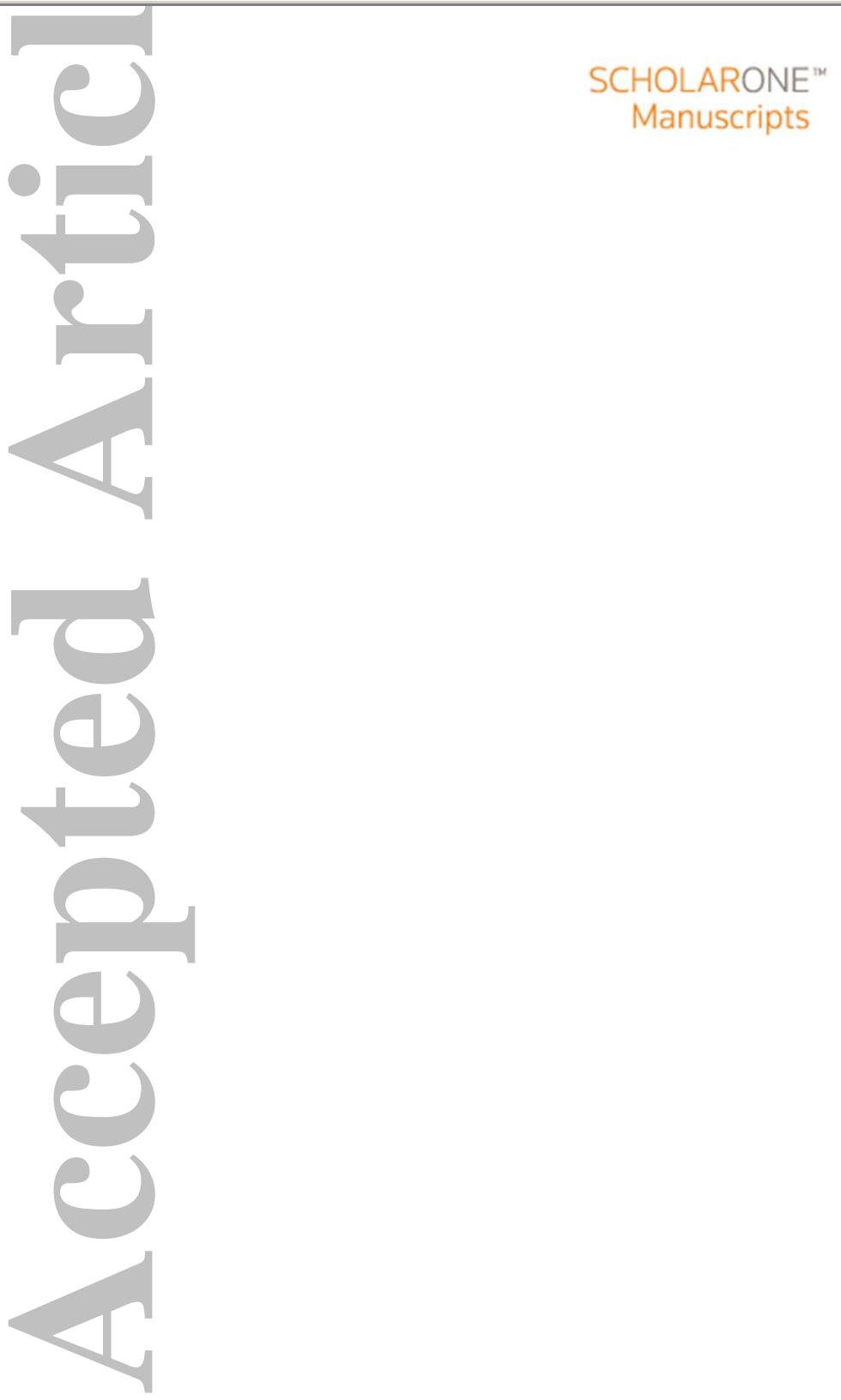

This is the author manuscript accepted for publication and has undergone full peer review but has not been through the copyediting, typesetting, pagination and proofreading process, which may lead to differences between this version and the Version record. Please cite this article as doi:10.1002/ mds.26569. 


\section{A Placebo-Controlled Trial of AQW051 in Patients with Moderate to Severe Levodopa-Induced}

\section{Dyskinesia}

Claudia Trenkwalder, ${ }^{1-3}$ Daniela Berg, ${ }^{3,4}$ Olivier Rascol, ${ }^{5,6}$ Karla Eggert, ${ }^{3,7}$ Andres Ceballos-Baumann, ${ }^{3,8}$ Jean-Christophe Corvol, ${ }^{6,9}$ Alexander Storch, ${ }^{3,10}$ Lin Zhang, ${ }^{11}$ Jean-Philippe Azulay, ${ }^{6,12}$ Emmanuel Broussolle, ${ }^{6,13,14}$ Luc Defebvre, ${ }^{6,15}$ Christian Geny, ${ }^{6,16}$ Michal Gostkowski, ${ }^{17}$ Fabrizio Stocchi, ${ }^{18}$ Christine Tranchant, ${ }^{6,19}$ Pascal Derkinderen, ${ }^{6,20}$ Franck Durif, ${ }^{6,21}$ Alberto J. Espay, ${ }^{22}$ Andrew Feigin, ${ }^{23}$ Jean-Luc Houeto, ${ }^{6,24}$ Johannes Schwarz, ${ }^{3,25}$ Thérèse Di Paolo, ${ }^{26,27}$ Dominik Feuerbach, ${ }^{28}$ Hans-Ulrich Hockey, ${ }^{28,29}$ Judith Jaeger, ${ }^{30}$ Annamaria Jakab, ${ }^{28}$ Donald Johns, ${ }^{31}$ Gurutz Linazasoro, ${ }^{32}$ Paul Maruff, ${ }^{33}$ Izabela Rozenberg, ${ }^{28}$ Judit Sovago, ${ }^{28}$ Markus Weiss, ${ }^{28}$ and Baltazar Gomez-Mancilla ${ }^{28,34 *}$

${ }^{1}$ Paracelsus-Elena Hospital, Kassel, Germany

${ }^{2}$ Department of Neurosurgery, University Medical Center, Goettingen, Germany

${ }^{3}$ German Parkinson Study Group

${ }^{4}$ Department of Neurodegeneration, Hertie-Institute for Clinical Brain Research and German Center for Neurodegenerative Diseases, Tübingen, Germany

${ }^{5}$ Department of Clinical Pharmacology and Neurosciences, NeuroToul Excellence Center for Neurodegenerative Disorders, University UPS of Toulouse III, CIC-9302/INSERM UMR825, Hôpital

Purpan - Pavillon Riser, Toulouse, France

${ }^{6}$ NS PARK/FCRIN network, France

${ }^{7}$ Department of Neurology, Philipps-University of Marburg, Germany

${ }^{8}$ Schön Klinik München-Schwabing, München, Germany

${ }^{9}$ Sorbonne Universités, UPMC Univ Paris 06, and INSERM UMRS $1127 / C I C-1422$, and CNRS UMR

7225, and AP-HP, and ICM, Hôpital Pitié-Salpêtrière, Département des maladies du système nerveux,

Paris, France

John Wiley \& Sons

This article is protected by copyright. All rights reserved. 
${ }^{10}$ Division of Neurodegenerative Diseases, Department of Neurology, Dresden University of Technology, Dresden, Germany

${ }^{11}$ Department of Neurology, UC Davis MIND Institute, Sacramento, CA, USA

${ }^{12}$ Service de Neurologie et pathologie du Mouvement, Hôpital de la Timone, Marseille Cedex, France

${ }^{13}$ Univisité Lyon 1; Hospices Civils de Lyon, Hôpital Neurologique Pierre Wertheimer, Service de Neurologie C, 69003 Lyon, France

(

${ }^{14}$ CNRS UMR 5229, Centre de Neurosciences Cognitives, Team Basal Ganglia, 69500 Bron, France

${ }^{15}$ Service de Neurologie et Pathologie du movement, EA 1046, CHU de Lille, Hôpital Roger Salengro, Lille, France

${ }^{16}$ Movement to Health (M2H) laboratory, Euromov, University Montpellier 1, Hôpital gui de Chauliac, Montpellier, France

${ }^{17}$ Center for Neurological Restoration, Cleveland Clinic, Cleveland, $\mathrm{OH}$, USA

${ }^{18}$ Department of Neurology, Institute for Research and Medical Care, IROCS, Rome, Italy

${ }^{19}$ Service de Neurologie, Hôpital de Hautepierre, Strasbourg

${ }^{20}$ Centre Investigation Clinique Neurologie, CHU Nantes, Hôpital G\&R Laennec, Nantes, France

${ }^{21}$ Service de Neurologie, Hôpital Gabriel Montpied, Clermont-Ferrand, France

${ }^{22}$ Department of Neurology, James J. and Joan A. Gardner Family Center for Parkinson's Disease and Movement Disorders, University of Cincinnati Academic Health Center, Cincinnati, $\mathrm{OH}$, USA

${ }^{23}$ Feinstein Institute for Medical Research, North Shore - LIJ Health System, Manhasset, NY, USA

${ }^{24}$ Service de Neurologie, CIC-INSERM 1402, CHU de Poitiers, Université de Poitiers, Poitiers, France

${ }^{25}$ Klinik Haag, Haag, Germany

${ }^{26}$ Neuroscience Research Unit, Centre de recherche du CHU de Québec, Québec, Canada 
${ }^{27}$ Faculty of Pharmacy, Laval University, Québec, Canada

${ }^{28}$ Novartis Institutes for BioMedical Research, Basel, Switzerland

${ }^{29}$ Biometrics Matters Ltd, Hamilton, New Zealand

${ }^{30}$ Albert Einstein College of Medicine, NY and CognitionMetrics, LLC, DE, USA

${ }^{31}$ Novartis Pharmaceuticals Corporation, East Hanover, NJ, USA

${ }^{33}$ Inbiomed, San Sebastian, Spain

$\checkmark$

${ }^{31}$ CogState, Inc., New Haven, CT, USA

${ }^{34}$ Department of Neurology and Neurosurgery, McGill University, Montreal, Québec, Canada

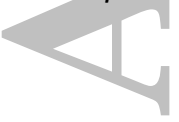

${ }^{*}$ Corresponding author:

$r($

B Gomez-Mancilla, MD PhD

Executive Director, Neuroscience Translational Medicine

Novartis Institutes for BioMedical Research

WSJ.210.25.5

WS

CH-4056 Basel

Car

Switzerland

Tel: +41 61324 0164; Email: baltazar.gomezmancilla@novartis.com

Word count: 1682 (limit = 1700; excluding abstract, acknowledgements, references, figure legends)

Figure/table count: 2 figures/tables (limit $=2$ ) 
Running title: AQW051 in levodopa-induced dyskinesia (character count: 37 inc spaces; limit = 45 letters inc spaces)

Key words: Parkinson's disease; levodopa (L-dopa); nicotinic acetylcholine receptor agonist (nAChR) a7; AQW051; dyskinesias

\section{Funding sources for study:}

1

This research is sponsored by Novartis Pharmaceuticals, Basel, Switzerland, and also in part by the French “Investissement d'Avenir” program (ANR-10-IAIHU-06). Financial support for medical editorial assistance was provided by Novartis Pharmaceuticals, Basel, Switzerland.

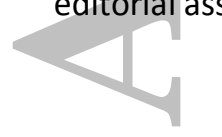

\section{Financial disclosure/conflicts of interest related to research covered in this article:}

Claudia Trenkwalder, Daniela Berg, Olivier Rascol, Karla Eggert, Alexander Storch, and Emmanuel Broussolle have served on advisory boards for Novartis. Claudia Trenkwalder has served on advisory (boar

boards and has received honoraria from Britannia, Mundipharma, UCB and Desitin; has received honoraria from UCB, Desitin Arzneimittel GmbH, and Vifor; and has received grants from Teva, Mundipharma, Michael J. Fox, BmBF, and EU Horizon 2020. Olivier Rascol has served on advisory boards for AbbVie, Addex, Britannia, Lundbeck, Merck, Sanofi-Aventis, Servier, Teva, UCB, XenoPort, and Zambon; received honoraria from AbbVie, Britannia, Lilly France, Lundbeck, Merck, MDS, NeuroDerm, Osmotica, Servier, Teva, UCB, and Zambon; and received grants from Agence Nationale de la Recherche (ANR), CHU de Toulouse, France-Parkinson, INSERM-DHOS Recherche Clinique Translationnelle, Michael J. Fox Foundation, Programme Hospitalier de Recherche Clinique, Boehringer Ingelheim, Lundbeck, Teva, and UCB. Andres Ceballos-Baumann, Jean-Christophe Corvol, Luc Defebvre, and Christian Geny have received honoraria from Novartis. Johannes Schwarz and Gurutz Linazasoro have served as consultants for Novartis and have received honoraria from Novartis; Gurutz Linazasoro has also served on advisory boards for Novartis. Fabrizio Stocchi has 
served on advisory boards and received honoraria from Novartis. Franck Durif has served on advisory boards for Novartis. Thérèse Di Paolo has a collaborative research contract with Novartis Pharma AG for investigating new compounds in vivo, and is also a co-author on patents with (a) Novartis Pharma AG. Hans-Ulrich Hockey is an employee of Biometrics Matters Ltd (BML) and served as a contracted statistical consultant to Novartis Pharma AG when working on this article. Paul Caruffis a Maruff is a full-time employee of CogState Ltd, and Judith Jaeger was a full-time employee of CogState Ltd at the time of the study. Annamaria Jakab and Judit Sovago are employees of Novartis Cogstate Pharma AG. Baltazar Gomez-Mancilla, Dominik Feuerbach, Izabela Rozenberg, and Markus Weiss are employees of, and hold shares in, Novartis Pharma AG; Markus Weiss is also a Novartis patent holder. Donald Johns was a full-time employee of Novartis at the time of the study. Alberto Espay, Lin Zhang, Jean-Philippe Azulay, Michal Gostkowski, Christine Tranchant, Pascal Derkinderen, Andrew Feigin, and Jean-Luc Houeto have declared no financial conflicts of interest related to research covered in this article.

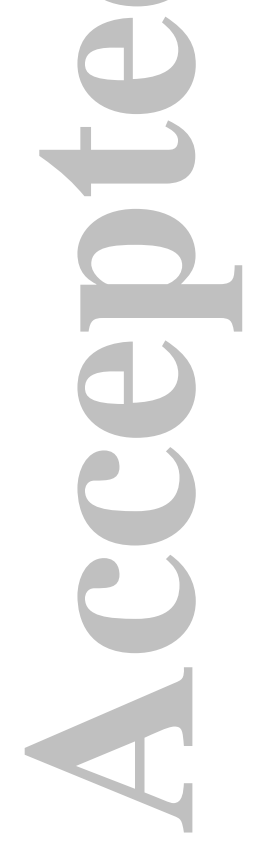




\section{Abstract [Word count: $146(\max 150)]$}

\section{Introduction}

This Phase II, randomized, double-blind, placebo-controlled study evaluated the efficacy and safety of the nicotinic acetylcholine receptor $\alpha 7$ agonist, AQW051, in patients with Parkinson's disease and levodopa-induced dyskinesia.

\section{Methods}

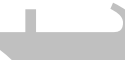

Patients with idiopathic Parkinson's disease and moderate to severe levodopa-induced dyskinesia were randomized to AQW051 $10 \mathrm{mg}(n=24)$, AQW051 $50 \mathrm{mg}(\mathrm{n}=24)$, or placebo $(n=23)$ once daily for 28 days. Co-primary endpoints were change in Modified Abnormal Involuntary Movement Scale and Unified Parkinson's Disease Rating Scale part III scores. Secondary outcomes included pharmacokinetics.

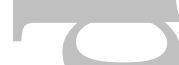

Results

In total, 67 patients completed the study. AQW051-treated patients experienced no significant (1)

improvements in Modified Abnormal Involuntary Movement Scale or Unified Parkinson's Disease

Rating Scale part III scores by day 28. AQW051 was well tolerated; the most common adverse events were dyskinesia, fatigue, nausea, and falls.

\section{Conclusions}

AQW051 did not significantly reduce dyskinesia or parkinsonian severity. 


\section{Introduction}

Motor complications such as levodopa (L-dopa)-induced dyskinesia (LID) negatively impact the lives of patients with Parkinson's disease (PD), ${ }^{1-3}$ and there are few sustained, non-invasive treatments for LID that do not reduce the antiparkinsonian benefits of L-dopa. Amantadine is currently the sole medication available and recommended for the management of LID. ${ }^{4}$ However, not all patients respond to or tolerate amantadine, and the prescription of amantadine is restricted by regulatory guidance in some countries (e.g. in Germany ${ }^{5}$ ).

Nicotine has been shown to protect against or alleviate nigrostriatal damage ${ }^{6-11}$ and improve LID $^{12-14}$ in parkinsonian animal models. The antidyskinetic and neuroprotective effects of nicotine are exerted via multiple nicotinic acetylcholine receptors (nAChRs). ${ }^{6,10,12,13,15-17}$ The antidyskinetic potential of $\alpha 7$ nAChR agonists has now been displayed in vivo using the novel, selective partial agonist, (R)-3-(6-p-Tolyl-pyridin-3-yloxy)-1-aza-bicyclo(2.2.2)octane (AQW051). ${ }^{18}$ AQW051 significantly reduced dyskinesia in 1-methyl-4-phenyl-1,2,3,6-tetrahydropyridine (MPTP)-lesioned monkeys without compromising the benefits of L-dopa. ${ }^{19}$ The objective of the current study was to evaluate the efficacy and safety of AQW051 in patients with moderate to severe PD-LID. As preclinical and clinical evidence suggests that $\alpha 7$ nAChR agonists, including AQW051, can also improve cognition, ${ }^{20-32}$ AQW051 was also evaluated for pro-cognitive effects in a post-hoc exploratory analysis.

\section{Methods}

This was a Phase II, multicenter, randomized, double-blind, parallel-group, placebo-controlled multidose study in PD-LID. Eligible patients were non-smoking men and women, aged 30-85 years, with idiopathic PD as per the UK Parkinson's Disease Society Brain Bank criteria. Patients were required to have: LID > 20\% (Unified Parkinson's Disease Rating Scale [UPDRS] item 32 rating $\geq 1$ ) of moderate to severe intensity (UPDRS item 33 rating $\geq 2$ ) ${ }^{33}$ LID for $\geq 3$ months before randomization; received L-dopa for $\geq 3$ years; stable treatment with L-dopa for $\geq 1$ month before randomization. Other 
concomitant antiparkinsonian medication was allowed if treatment was stable for $\geq 1$ month prior to randomization. Treatment with amantadine, antidepressants (except strong cytochrome [CYP]1A2 and CYP3A4 inhibitors), and/or benzodiazepines were permitted provided the dosing regimen was stable for $\geq 1$ month before randomization.

Patients were randomized at a ratio of 1:1:1 into one of three treatment groups: AQW051 $50 \mathrm{mg}$, AQW051 $10 \mathrm{mg}$, or placebo. Treatment was administered orally, once daily in the morning after the initial L-dopa dose, for a period of 28 days, with a 2-week follow-up. Assessments were performed every week, once during follow-up, and at the end of study visit.

The protocol and amendments were approved by the Independent Ethics Committee and Institutional Review Board at each study center. This study was conducted according to the ethical principles of the Declaration of Helsinki and was registered on ClinicalTrials.gov (identifier NCT01474421). Informed written consent was obtained from all patients.

\section{Outcomes}

The co-primary outcome measures were the Modified Abnormal Involuntary Movement Scale $(\text { mAIMS) })^{34}$ and UPDRS-III items $18-31,{ }^{35}$ respectively. Assessments were performed in the morning 1 $\mathrm{h}$ post L-dopa dose during ON-time and in the afternoon at a patient-specific time point.

Secondary outcome measures included: UPDRS-IV items 32-33, Lang-Fahn Activities of Daily Living and Dyskinesia Scale (LFADLDS) sum score, ${ }^{36}$ and a cognitive test battery (CogState) ${ }^{37}$ for safety analysis and for tracking potential pro-cognitive effects.

\section{Pharmacokinetics}

Blood samples ( $3 \mathrm{~mL}$ ) were collected into EDTA-containing tubes according to a predefined schedule. Sampling took place pre-dose and on days $1,8,16,21$, and $28 ; 1,3,4,5,8$, and $12 \mathrm{~h}$ post-dose on day 28; and before and after the assessments on day 32. Plasma concentrations of AQW051 were 
quantified using a validated liquid chromatography tandem mass spectrometry method (HPLC-

MS/MS). The lower limit of quantification was $0.050 \mathrm{ng} / \mathrm{mL}$ using $0.200 \mathrm{~mL}$ of plasma.

\section{Safety}

Assessments included adverse events (AEs) and serious AEs (SAEs) reporting, laboratory tests, vital signs, electrocardiograms, and use of the Columbia-Suicidality Severity Rating Scale (C-SSRS).

\section{Statistical analysis}

Stati

Descriptive statistics were used to summarize AEs, safety, and demographic variables for the safety population (all patients who received $\geq 1$ dose of study drug). Analysis of covariance of change from baseline of the per protocol population (all patients with $\geq 1$ post-randomization efficacy assessment and no protocol deviations nor withdrawn) was the primary analysis, with relevant baseline values as the covariate and treatment group as a fixed factor. The effect over placebo was estimated for each AQW051 dose using a Dunnett adjustment, and there were no corrections for multiple comparisons between variables.

The pharmacokinetic parameters at steady state: maximum plasma concentration $\left(C_{\max }\right)$, time to maximum plasma concentration $\left(\mathrm{T}_{\max }\right)$, area under the curve for $0-24 \mathrm{~h}\left(\mathrm{AUC}_{0-24 h}\right)$, and oral clearance (CL/F) were determined using non-compartmental methods and summarized by dose group using descriptive statistics for the PK population (all patients with valid PK data).

\section{Results}

Seventy-one patients were randomized to receive AQW051 $10 \mathrm{mg}(\mathrm{n}=24)$, AQW051 $50 \mathrm{mg}(\mathrm{n}=24)$, or placebo $(n=23) ; 67$ patients completed the study and 63 did so without protocol deviations. Patient demographics and clinical variables for the safety population are summarized in Table 1. Efficacy 
The study did not meet its primary endpoints, with change in mean sum score for mAIMS and UPDRS-III showing no significant improvements in LID or parkinsonian symptoms following AQW051 treatment at either dose (Table 2).

\section{Cognitive function}

In the primary analysis, AQW051 was not associated with statistically significant improvements in cognitive outcomes. However, exploratory repeated measures analysis of the safety population showed that compared with placebo, AQW051 $50 \mathrm{mg} /$ day yielded a change corresponding to a standardized effect size of $0.5(P=0.024)$ in the CogState memory composite scores and an effect size of $0.4(P=0.073)$ was seen for AQW051 $10 \mathrm{mg} /$ day. The individual memory tasks included in the memory composite (One-Back Task [ONB] + International Shopping List Task [ISL]) also improved moderately at both AQW051 doses, with improvements in the ISL at AQW051 $50 \mathrm{mg} /$ day reaching significance $(P=0.048)$.

\section{Pharmacokinetics}

Comparison of pre-dose plasma concentrations of AQW051 indicates steady state was reached within the first week of dosing. At day $28, \mathrm{~T}_{\max }$ median (range) values were very similar for 10 and $50 \mathrm{mg} /$ day; $5.00 \mathrm{~h}$ (2.92-11.9) and $4.99 \mathrm{~h}$ (3-8), respectively. Mean (SD) CL/F values were 88.8 (68.4) L/h and 102 (59.2) L/h at 10 and $50 \mathrm{mg} /$ day, respectively. Exposure in terms of $\mathrm{AUC}_{0-24 \mathrm{~h}}$ and $\mathrm{C}_{\max }$ increased $4.3(160-686 \mathrm{ng} * \mathrm{~h} / \mathrm{mL})$ and 4.5 -fold $(8.62-38.7 \mathrm{ng} / \mathrm{mL})$, respectively, with a 5 -fold increase of dose from 10 to $50 \mathrm{mg}$ suggesting dose proportionality in systemic exposure across the dose range for AQW051.

\section{Safety}

AEs were experienced by 18 patients receiving AQW051 10 mg/day, 15 receiving AQW051 $50 \mathrm{mg} /$ day, and 18 receiving placebo. They were mostly mild to moderate, with dyskinesia the most frequently reported $\mathrm{AE}$ across all treatment groups $(4.2 \%, 25.0 \%$, and $13.0 \%$ of patients in the $10 \mathrm{mg} /$ day, $50 \mathrm{mg} /$ day, and placebo groups, respectively). Nausea $(20.8 \%, 4.2 \%$, and $0 \%$, 
respectively), falls $(8.3 \%, 12.5 \%$, and $4.3 \%$, respectively) and fatigue $(8.3 \%, 8.3 \%$, and $8.7 \%$, respectively) were the next most commonly reported AEs overall after dyskinesia.

Two patients receiving AQW051 $50 \mathrm{mg} /$ day experienced SAEs (one case each of mild ON-OFF phenomenon and severe neuroborreliosis). These were not considered to be treatment-related by the investigators and no action regarding study medication was taken. In both cases the event had resolved on follow-up. Two patients experienced AEs that the investigators considered treatment-

related and resulted in their withdrawal from the study. One patient reported worsening dyskinesia on day 2 after treatment with AQW051 $50 \mathrm{mg} /$ day; the dyskinesia was ongoing at the last follow-up on day 21 , and no further follow-ups have been reported. The second patient (with an active history of depression) reported mild depression on day 11 of treatment with AQW051 $10 \mathrm{mg} /$ day. Her depression had resolved when followed up 12 months later.

\section{Discussion}

AQW051 treatment did not significantly improve dyskinesia or parkinsonian symptoms when using the primary endpoint of change in mAIMS or UPDRS-III scores. Our findings contrast with the current understanding of nicotinic receptor function in the basal ganglia, and preclinical efficacy of AQW051 in the LID primate model. ${ }^{19}$ This forces us to reconsider the hypothesis of targeting the alpha7 nicotinic receptors to suppress LID in humans. However, a variety of factors may explain these negative results without invalidating the concept, such as a sub-therapeutic dosing of AQW051 for PD-LID; a lack of sensitivity of mAIMS in measuring treatment-related changes in PD-LID; ${ }^{38}$ or a low comparability between groups for exposure to amantadine and potential effect on response to AQW051. The significant variability of dyskinesia among patients should not be overlooked as a reason for the study not meeting its primary endpoints, as biphasic dyskinesias were not separately reported in this study and may have different pathological mechanisms and pharmacological responses than peak-dose LIDs. 
A possible benefit for AQW051 in cognition was observed following a post-hoc exploratory analysis. Moderate treatment effects were observed on memory tasks of consistent magnitude and several differences to placebo were statistically significant. These exploratory results are supported by the preclinical cognitive-enhancing potential of AQW051 and other nAChR alpha7 agonists, ${ }^{20-28}$ and clinical findings in healthy male subjects ${ }^{29}$ and patients with schizophrenia. ${ }^{30-32}$ These findings reinforce the concept that neuropsychological and behavioral assessments should be considered as part of future studies evaluating these compounds.

AQW051 was well tolerated and the majority of AEs were mild to moderate in severity. AQW051 did A not cause any psychiatric AEs in patients with advanced PD who are known to be at high risk for developing these side effects with various drugs. This observation might echo some positive signals discussed previously, although the limited size of the sample and short duration of follow-up prevent any firm conclusion. The higher incidence of dyskinesia as an AE within the $50 \mathrm{mg}$ AQW051 group was unexpected. This might be related to some disparity between the treatment groups that occurred by chance at randomization. Patients in the $50 \mathrm{mg}$ AQW051 group received higher mean daily doses of L-dopa and were more frequently exposed to amantadine, with the risk of potential unknown pharmacodynamic drug interactions.

In conclusion, AQW051 did not significantly reduce dyskinesia or parkinsonian severity when using the primary endpoints of change in mAIMS and UPDRS. Further effects of this drug need to be explored with more specific trial designs and larger patient populations. 


\section{Acknowledgments}

We wish to thank the following investigators: S. Arguillère, I. Benatru, A.M. Bonnet, T. Boraud, K. Brockmann, M. Canelo, M. Charif, B. Debilly, K. Dujardin, U. Fietzek, A. Fradet, M. Galitzky, J. Godau, A.E. Haraszti, O. Lagha-Boukbiza, N. Longato, A. Noda, C. Nölker, C. Oehlwein, H. Pape, F. Pineau, T. Rouaud, I. Roullet Solignac, F. Tison, L. Vacca, D. Vadasz, B. Wieder, and T. Witjas; we also thank the following nurses and research technicians: F. Evano, M. France Le Labousse, P. Marc, L. Marquine, and C. Souyris, for their support during the study. We are grateful to the administrative support provided by N. Barun, S. Bernard, V. Chaigneau, E. Dellapina, M. Gaboreau, P. Gauteul, C. Hourquin, S. Ledily, E. Rabois, and C. Rouges, who helped co-ordinate the study as part of the French NS PARK network. We wish to thank Dr Martina Müngersdorf and Dr Christian Oehlwein for their involvement in the early development of this manuscript. We also thank Georgina Collett, PhD, of iMed Comms, an Ashfield Company, part of UDG Healthcare plc (funded by Novartis Pharmaceuticals, Basel, Switzerland) for medical editorial assistance with this manuscript. We thank the patients who participated in this study.

\section{Author roles in manuscript}

Conception and design of study: Baltazar Gomez-Mancilla, Thérèse Di Paolo, Dominik Feuerbach, Markus Weiss, Paul Maruff, Donald Johns

Acquisition, analysis, and interpretation of data: Baltazar Gomez-Mancilla, Claudia Trenkwalder, Olivier Rascol, Karla Eggert, Andrew Feigin, Paul Maruff (specifically, cognition readouts), Annamaria Jakab (specifically, bioanalytical quantification of PK samples), Alberto Espay, Donald Johns, Fabrizio Stocchi

Acquisition of data: Claudia Trenkwalder, Daniela Berg, Andres Ceballos-Baumann, Jean-Christophe Corvol, Alexander Storch, Lin Zhang, Emmanuel Broussolle, Christian Geny, Michal Gostkowski, Johannes Schwarz, Izabela Rozenberg, Jean-Philippe Azulay, Christine Tranchant, Pascal Derkinderen, Franck Durif, Jean-Luc Houeto 
Analysis and interpretation of data: Luc Defebvre, Hans-Ulrich Hockey, Gurutz Linazasoro, Judit Sovago, Markus Weiss (PK data)

Statistical expertise: Baltazar Gomez-Mancilla, Hans-Ulrich Hockey, Paul Maruff

Drafting of all or part of the manuscript: Baltazar Gomez-Mancilla, Claudia Trenkwalder, Thérèse Di Paolo, Dominik Feuerbach, Annamaria Jakab, Paul Maruff, Donald Johns

Critical revision of manuscript for important intellectual content: Baltazar Gomez-Mancilla, Claudia Trenkwalder, Daniela Berg, Olivier Rascol, Karla Eggert, Andres Ceballos-Baumann, Jean-Christophe Corvol, Alexander Storch, Lin Zhang, Emmanuel Broussolle, Luc Defebvre, Michal Gostkowski, Andrew Feigin, Johannes Schwarz, Thérèse Di Paolo, Hans-Ulrich Hockey, Judith Jaeger, Annamaria Jakab, Paul Maruff, Gurutz Linazasoro, Izabela Rozenberg, Judit Sovago, Markus Weiss, Jean-Philippe Azulay, Dominik Feuerbach, Christine Tranchant, Pascal Derkinderen, Frank Durif, Alberto Espay, Jean-Luc Houeto, Fabrizio Stocchi

Proofreading: Hans-Ulrich Hockey

Administrative, technical, or material support: Baltazar Gomez-Mancilla, Claudia Trenkwalder, Daniela Berg, Karla Eggert, Andres Ceballos-Baumann, Emmanuel Broussolle, Judith Jaeger, Gurutz Linazasoro, Paul Maruff, Izabela Rozenberg, Judit Sovago, Jean-Luc Houeto, Donald Johns Supervision: Baltazar Gomez-Mancilla, Donald Johns, Claudia Trenkwalder, Johannes Schwarz, Annamaria Jakab, Jean-Philippe Azulay, Dominik Feuerbach, Franck Durif, Fabrizio Stocchi Obtaining funding: Baltazar Gomez-Mancilla, Donald Johns, Dominik Feuerbach

\section{Full financial disclosures of all authors for the past year}

Claudia Trenkwalder has served on advisory boards for Mundipharma, Britannia Pharma, UCB and Novartis; has received honoraria from UCB, Desitin Arzneimittel GmbH, and Vifor; and has received grants from Teva, Mundipharma, Michael J. Fox, BmBF, and EU Horizon 2020. Daniela Berg has served on advisory boards for Novartis and UCB Pharma GmbH; has received speaker honoraria from 
Lundbeck, Teva, and UCB Pharma GmbH; and has received grants from Michael J. Fox Foundation, BmBF (German Federal Ministry of Education and Research), dPV (German Parkinson's Association), Internationale Parkinson Fonds Deutschland GmbH, Janssen Pharmaceutica, Teva Pharma GmbH, and UCB Pharma GmbH. Olivier Rascol has served on advisory boards for AbbVie, Addex, Britannia, Lundbeck, Merck, Sanofi-Aventis, Servier, Teva, UCB, XenoPort, and Zambon; received honoraria from AbbVie, Britannia, Lilly France, Lundbeck, Merck, MDS, NeuroDerm, Osmotica, Servier, Teva, UCB, and Zambon; and received grants from Agence Nationale de la Recherche (ANR), $C H U$ de Toulouse, France-Parkinson, INSERM-DHOS Recherche Clinique Translationnelle, Michael J. Fox Foundation, Programme Hospitalier de Recherche Clinique, Boehringer Ingelheim, Lundbeck, Teva, and UCB. Karla Eggert has served as a consultant for Desitin Arzneimittel GmbH, Novartis, Zambon, Solvay Pharmaceuticals, and UCB; served on advisory boards for Medtronic, Merck Sharp \& Dohme, Novartis, Zambon, and UCB; received honoraria from Abbott Arzneimittel GmbH, Boehringer Ingelheim, Desitin Arzneimittel GmbH, Meda Pharma, Novartis, Zambon, Teva, and UCB; and received scientific grants from the German Ministry of Education and Health, and the Pitzer Foundation. Andres Ceballos-Baumann has served on advisory boards for AbbVie, Archimedes, Desitin Arzneimittel GmbH, Ipsen, Licher MT, Merz Pharmaceuticals, Meda, Medtronic, and UCB; received honoraria from AbbVie, Allergan, Archimedes, BIAL, Bioprojet, Desitin Arzneimittel GmbH, Ipsen, Licher MT, Meda, Merz Pharmaceuticals, Medtronic, Neurosearch, Novartis, Teva, and UCB; and received research grants from Deutsche Parkinson Vereinigung e.V., Verein zur Förderung de Behandlung und Betreuung neurologisch Kranker e.V., and Deutsche Stiftung Neurologie. JeanChristophe Corvol has stock ownership in B\&A Therapeutics; partnerships with Sanofi-Aventis; received honoraria from BIAL and Novartis; and received research grants from Michael J. Fox Foundation, Programme Hospitalier de Recherche Clinique, Agence Nationale pour la recherché (ANR), Innovative Medicine Initiative (IMI), and travel grants from Teva and UCB. Alexander Storch is employed by the non-profit federal government organizations, Dresden University of Technology, University Clinics, and German Center for Neurodegenerative Diseases (DZNE); has served as a 
consultant for Britannia, GKC Melbourne, and Mundipharma; served on advisory boards for AbbVie, Desitin, Elblandkliniken Meissen, GlaxoSmithKline, Klinik Tharandter Wald, Klinikum Dessau, MEDA Pharma, Medtronic, Mundipharma, Teva, and UCB; and received research grants from GKC, Teva (unrestricted clinical study grants), German Federal Ministry of Education and Research, German Federal Ministry of Economy, German Research Association (DFG), Helmholtz Association Germany (through DZNE), NCL Foundation, NA Advocacy, and the International Parkinson Foundation (all research grants, non-profit organizations). Jean-Philippe Azulay has served as a consultant for, and on advisory boards for, AbbVie, Lundbeck, Medtronic, Novartis, Teva, and UCB. Emmanuel Broussolle has served on advisory boards for AbbVie, Lundbeck, Novartis, Teva, and UCB, and received travel funding from Novartis, Teva, and UCB. Luc Defebvre has served as a consultant to AbbVie, and received honoraria from Novartis and Teva. Christian Geny has served on advisory boards and received honoraria from Novartis. Fabrizio Stocchi has served on advisory boards, acted as a consultant and received honoraria from Chiesi, GlaxoSmithKline, Lundbeck, IMPAX, Merck, Novartis, Teva, UCB, and Zanbon. He has also served on an advisory board and received honoraria from Britannia. Christine Tranchant has served on advisory boards for Allergan and acted as a consultant for Teva. Pascal Derkinderen has received grant support from Michael J. Fox Foundation. Franck Durif has served on advisory boards for AbbVie, Allergan, Lundbeck, Novartis, and Teva, and has a contract with Lundbeck. He has received grant support from Association France Parkinson, Fédération de Recherché pour le Cerveau, Fondation de l'Avenir, and the French Ministry of Health. Alberto Espay is supported by the National Institute of Health [NIH] (K23MH092735) and has received grant support from CleveMed/Great Lakes Neurotechnologies, Davis Phinney Foundation, and Michael J. Fox Foundation; personal compensation as a consultant/scientific advisory board member for Solvay, Abbott, Chelsea Therapeutics, Teva, Impax, Merz, Lundbeck, and Eli Lilly; and honoraria from TEVA, UCB, the American Academy of Neurology, and the Movement Disorders Society; and publishing royalties from Lippincott Williams \& Wilkins and Cambridge University Press. Andrew Feigin has served as a consultant to Third Rock Ventures and Vaccinex, Inc., and received 
grants from National Institute of Neurological Disorders and Stroke (NINDS). Jean-Luc Houeto has served as a consultant for Abbott, AbbVie, Lundbeck-Teva, and UCB and participated in advisory boards for AbbVie, Lundbeck, and Novartis. Johannes Schwarz has served as a consultant for Boehringer Ingelheim, Desitin Arzneimittel GmbH, Novartis, and UCB, and received honoraria from

AbbVie, Boehringer Ingelheim, Desitin Arzneimittel GmbH, Licher MT GmbH, Novartis, and UCB. Thérèse Di Paolo has served as a consultant to Biotic; received grants from the Canadian Institutes of Health Research (CIHR), Quebec Consortium for Drug Discovery (CQDM), and Natural Sciences and Engineering Research Council of Canada (NSERC); has collaborative research contracts with Novartis Pharma AG and Prexton Therapeutics for investigating new compounds in vivo; and is a co-author on patents with Novartis Pharma AG. Gurutz Linazasoro has served as a consultant to, received honoraria from, and served on advisory boards for Novartis. Hans-Ulrich Hockey is an employee of Biometrics Matters Ltd (BML) and is serving as a contracted statistical consultant to Auckland Hospital Board, Fisher and Paykel Healthcare, Manuka Health, and Novartis Pharma AG. Paul Maruff is a full-time employee of CogState Ltd. Judith Jaeger was a full-time employee at CogState Ltd at the time of the study. She is now President and Principal Scientist at CognitionMetrics, LLC. Annamaria Jakab and Judit Sovago are employees of Novartis Pharma AG. Baltazar Gomez-Mancilla, Dominik Feuerbach, Izabela Rozenberg, and Markus Weiss are employees of, and hold shares in, Novartis Pharma AG; Markus Weiss is also a Novartis patent holder. Donald Johns was a full-time employee of Novartis at the time of the study. He is now a full-time employee of, and holds shares in, Biogen. Michal Gostkowski and Lin Zhang have declared no financial interests for the previous 12 months. 


\section{References}

1. Fabbrini G, Brotchie JM, Grandas F, Nomoto M, Goetz CG. Levodopa-induced dyskinesias. Mov Disord 2007;22:1379-1389.

2. Ahlskog JE, Muenter MD. Frequency of levodopa-related dyskinesias and motor fluctuations as estimated from the cumulative literature. Mov Disord 2001;16:448-458.

3. Chapuis S, Ouchchane L, Metz O, Gerbaud L, Durif F. Impact of the motor complications of Parkinson's disease on the quality of life. Mov Disord 2005;20:224-230.

4. Seppi K, Weintraub D, Coelho M, et al. The Movement Disorder Society Evidence-Based Medicine Review Update: treatments for the non-motor symptoms of Parkinson's disease. Mov Disord 2011;26(Suppl 3):S42-S80.

5. ratiopharm $\mathrm{GmbH}$. Amantadin-ratiopharm $100 \mathrm{mg}$ Filmtabletten [in German]. Ulm, ratiopharm, 2010.

6. Huang LZ, Parameswaran N, Bordia T, Michael MJ, Quik M. Nicotine is neuroprotective when administered before but not after nigrostriatal damage in rats and monkeys. J Neurochem 2009;109:826-837.

7. Parain K, Marchand V, Dumery B, Hirsch E. Nicotine, but not cotinine, partially protects dopaminergic neurons against MPTP-induced degeneration in mice. Brain Res 2001;890:347350.

8. Quik M, Chen L, Parameswaran N, Xie X, Langston JW, McCallum SE. Chronic oral nicotine normalizes dopaminergic function and synaptic plasticity in 1-methyl-4-phenyl-1,2,3,6tetrahydropyridine-lesioned primates. J Neurosci 2006;26:4681-4689. 
9. Quik M, Parameswaran N, McCallum SE, et al. Chronic oral nicotine treatment protects against striatal degeneration in MPTP-treated primates. J Neurochem 2006;98:1866-1875.

10. Ryan RE, Ross SA, Drago J, Loiacono RE. Dose-related neuroprotective effects of chronic nicotine in 6-hydroxydopamine treated rats, and loss of neuroprotection in alpha4 nicotinic receptor subunit knockout mice. Br J Pharmacol 2001;132:1650-1656.

11. Visanji NP, O'Neill MJ, Duty S. Nicotine, but neither the alpha4beta2 ligand RJR2403 nor an alpha7 nAChR subtype selective agonist, protects against a partial 6-hydroxydopamine lesion of the rat median forebrain bundle. Neuropharmacology 2006;51:506-516.

12. Bordia T, Campos C, Huang L, Quik M. Continuous and intermittent nicotine treatment reduces L-3,4-dihydroxyphenylalanine (L-DOPA)-induced dyskinesias in a rat model of Parkinson's disease. J Pharmacol Exp Ther 2008;327:239-247.

13. Huang LZ, Campos C, Ly J, Ivy Carroll F, Quik M. Nicotinic receptor agonists decrease L-dopainduced dyskinesias most effectively in partially lesioned parkinsonian rats.

Neuropharmacology 2011;60:861-868.

14. Quik M, Cox H, Parameswaran N, O'Leary K, Langston JW, Di Monte D. Nicotine reduces levodopa-induced dyskinesias in lesioned monkeys. Ann Neurol 2007;62:588-596.

15. Stuckenholz V, Bacher M, Balzer-Geldsetzer M, et al. The alpha7 nAChR agonist PNU-282987 reduces inflammation and MPTP-induced nigral dopaminergic cell loss in mice. J Parkinsons Dis 2013;3:161-172.

16. Suzuki S, Kawamata J, Matsushita T, et al. 3-[(2,4-Dimethoxy)benzylidene]-anabaseine dihydrochloride protects against 6-hydroxydopamine-induced parkinsonian neurodegeneration through alpha7 nicotinic acetylcholine receptor stimulation in rats. J Neurosci Res 2013;91:462-471. 
17. Zhang D, Mallela A, Sohn D, et al. Nicotinic receptor agonists reduce L-DOPA-induced dyskinesias in a monkey model of Parkinson's disease. J Pharmacol Exp Ther 2013;347:225234.

18. Hurth K, Gomez-Mancilla B, Hoyer D, et al. Identification of AQW051, an alpha7 nicotinic acetylcholine receptor partial agonist for the treatment of cognitive impairment associated with schizophrenia. Abstract MEDI 222 at the Division of Medicinal Chemistry, 247th American Chemical Society (ACS) National Meeting, Dallas, Texas, USA, March 16-20, 2014.

19. Di Paolo T, Gregoire L, Feuerbach D, Elbast W, Weiss M, Gomez-Mancilla B. AQW051, a novel and selective nicotinic acetylcholine receptor $\alpha 7$ partial agonist, reduces L-Dopa-induced dyskinesias and extends the duration of L-Dopa effects in parkinsonian monkeys. Parkinsonism Relat Disord 2014;20:1119-1123.

20. Feuerbach D, Pezous N, Weiss M, Shakeri-Nejad K, Lingenhoehl K, Hoyer D, Hurth K, Bilbe G, Pryce CR, McAllister K, Chaperon F, Kucher K, Johns D, Blaettler T, Lopez Lopez C. AQW051, a novel, potent and selective $\alpha 7$ nicotinic ACh receptor partial agonist: pharmacological characterization and phase I evaluation. Br J Pharmacol. 2015;172:1292-304.

21. de Fiebre CM, Meyer EM, Henry JC, Muraskin SI, Kem WR, Papke RL. Characterization of a series of anabaseine-derived compounds reveals that the 3-(4)-dimethylaminocinnamylidine derivative is a selective agonist at neuronal nicotinic alpha 7/125I-alpha-bungarotoxin receptor subtypes. Mol Pharmacol 1995;47:164-171.

22. Feuerbach D, Nozulak J, Lingenhoehl K, McAllister K, Hoyer D. JN403, in vitro characterization of a novel nicotinic acetylcholine receptor alpha7 selective agonist. Neurosci Lett 2007;416:61-65. 
23. Feuerbach $D$, Lingenhoehl $K$, Olpe HR, et al. The selective nicotinic acetylcholine receptor alpha7 agonist JN403 is active in animal models of cognition, sensory gating, epilepsy and pain. Neuropharmacology 2009;56:254-263.

24. Hajos M, Hurst RS, Hoffmann WE, et al. The selective alpha7 nicotinic acetylcholine receptor agonist PNU-282987 [N-[(3R)-1-Azabicyclo[2.2.2]oct-3-yl]-4-chlorobenzamide hydrochloride] enhances GABAergic synaptic activity in brain slices and restores auditory gating deficits in anesthetized rats. J Pharmacol Exp Ther 2005;312:1213-1222.

25. Bitner R, Anderson D, Drescher K, et al. Preclinical characterization of a selective alpha-7 neuronal nicotinic acetylcholine receptor agonist ABT-126: a novel therapeutic agent for the treatment of cognitive impairment in Alzheimer's disease and schizophrenia. Alzheimers Dement 2013;9:P817-P818.

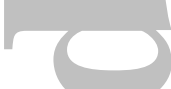

26. Hauser TA, Kucinski A, Jordan KG, et al. TC-5619: an alpha7 neuronal nicotinic receptorselective agonist that demonstrates efficacy in animal models of the positive and negative 1 symptoms and cognitive dysfunction of schizophrenia. Biochem Pharmacol 2009;78:803-812.

27. Mazurov AA, Kombo DC, Hauser TA, et al. Discovery of (2S,3R)-N-[2-(pyridin-3-ylmethyl)-1azabicyclo[2.2.2]oct-3-yl]benzo[b]furan-2-car boxamide (TC-5619), a selective alpha7 nicotinic acetylcholine receptor agonist, for the treatment of cognitive disorders. J Med Chem 2012;55:9793-9809.

27. Prickaerts J, van Goethem NP, Chesworth R, et al. EVP-6124, a novel and selective alpha7 nicotinic acetylcholine receptor partial agonist, improves memory performance by potentiating the acetylcholine response of alpha7 nicotinic acetylcholine receptors. Neuropharmacology 2012;62:1099-1110. 
29. Kitagawa H, Takenouchi T, Azuma R, et al. Safety, pharmacokinetics, and effects on cognitive function of multiple doses of GTS-21 in healthy, male volunteers. Neuropsychopharmacology 2003;28:542-551.

30. Olincy A, Harris JG, Johnson LL, et al. Proof-of-concept trial of an alpha7 nicotinic agonist in schizophrenia. Arch Gen Psychiatry 2006;63:630-638.

31. Lieberman JA, Dunbar G, Segreti AC, et al. A randomized exploratory trial of an alpha-7 nicotinic receptor agonist (TC-5619) for cognitive enhancement in schizophrenia.

Neuropsychopharmacology 2013;38:968-975.

32. Preskorn SH, Gawryl M, Dgetluck N, Palfreyman M, Bauer LO, Hilt DC. Normalizing effects of EVP-6124, an alpha-7 nicotinic partial agonist, on event-related potentials and cognition: a proof of concept, randomized trial in patients with schizophrenia. J Psychiatr Pract 2014;20:12-24.

33. Fahn S, Elton R, Members of the UPDRS Development Committee. Unified Parkinson's Disease Rating Scale. In: Fahn S, Marsden CD, Calne DB, Goldstein M. Eds. Recent developments in Parkinson's disease. Florham Park, NJ, Macmillan Healthcare Information, 1987; 153-164.

34. Guy W. Assessment Manual for Psychopharmacology: Revised (DHEW publication no. ADM 76338). Rockville, MD, US Department of Health, Education and Welfare; Public Health Service; Alcohol, Drug Abuse and Mental Health Administration; NIMH Psychopharmacology Research Branch; Division of Extramural Research Programs, 1976.

35. Marconi R, Lefebvre-Caparros D, Bonnet AM, Vidailhet M, Dubois B, Agid Y. Levodopa-induced dyskinesias in Parkinson's disease phenomenology and pathophysiology. Mov Disord 1994;9:2-12. 
36. Parkinson Study Group. Evaluation of dyskinesias in a pilot, randomized, placebo-controlled trial of remacemide in advanced Parkinson disease. Arch Neurol 2001;58:1660-1668.

37. Falleti MG, Maruff P, Collie A, Darby DG. Practice effects associated with the repeated assessment of cognitive function using the CogState battery at 10-minute, one week and one month test-retest intervals. J Clin Exp Neuropsychol 2006;28:1095-1112.

38. Goetz CG, Stebbins GT, Chung KA, et al. Which dyskinesia scale best detects treatment response? Mov Disord 2013;28:341-346.

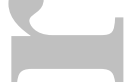

39. Litvan I, Goldman JG, Troster Al, et al. Diagnostic criteria for mild cognitive impairment in Parkin Parkinson's disease: Movement Disorder Society Task Force guidelines. Mov Disord 2012;27:349-356.

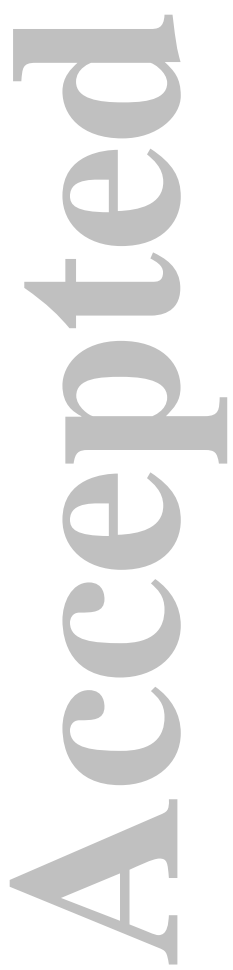


TABLE 1. Baseline patient characteristics and baseline CogState composite scores

\begin{tabular}{|c|c|c|c|}
\hline \multirow[t]{2}{*}{ Characteristic } & \multicolumn{2}{|c|}{ AQW051 } & \multirow{2}{*}{$\begin{array}{l}\text { Placebo } \\
(n=23)\end{array}$} \\
\hline & $10 \mathrm{mg}(\mathrm{n}=24)$ & $50 \mathrm{mg}(\mathrm{n}=24)$ & \\
\hline \multicolumn{4}{|l|}{ Age, years } \\
\hline Mean (SD) & $64.2(8.30)$ & $65.5(10.26)$ & $63.3(10.01)$ \\
\hline \multicolumn{4}{|l|}{ Sex, n (\%) } \\
\hline Male & $11(45.8)$ & $15(62.5)$ & $13(56.5)$ \\
\hline $\begin{array}{l}\text { Female } \\
\text { L-dopa equivalent dose, } \mathrm{mg} / \text { day }\end{array}$ & $13(54.2)$ & $9(37.5)$ & $10(43.5)$ \\
\hline Mean (SD) & 681.7 (389.49) & $919.6(523.0)$ & $767.4(368.0)$ \\
\hline \multicolumn{4}{|l|}{ Amantadine taken, $\mathbf{n}(\%)$} \\
\hline Yes & $4(16.7)$ & $9(37.5)$ & $8(34.8)$ \\
\hline $\begin{array}{l}\text { Mild to moderate depression, } n(\%)^{a} \\
\text { mAIMS score }\end{array}$ & $12(50)$ & $11(46)$ & $11(48)$ \\
\hline Mean (SD) & $9.38(3.61)$ & $11.44(4.59)$ & $11.76(5.08)$ \\
\hline \multicolumn{4}{|l|}{ UPDRS-III score } \\
\hline Mean (SD) & $17.65(8.18)$ & $14.92(7.28)$ & $18.46(11.14)$ \\
\hline \multicolumn{4}{|l|}{ LFADLDS score } \\
\hline Mean (SD) & $9.2(3.50)$ & $9.7(3.33)$ & $10.8(3.46)$ \\
\hline \multicolumn{4}{|l|}{ PD-MCl, n (\%) } \\
\hline Yes & $15(62.5)$ & $15(62.5)$ & $16(69.6)$ \\
\hline CogState composite scores & $n=23$ & $n=21$ & $n=21$ \\
\hline Psychomotor/attentional & 0.038 & -0.053 & 0.011 \\
\hline Executive function & 0.154 & 0.010 & -0.196 \\
\hline Memory & 0.192 & -0.111 & -0.103 \\
\hline
\end{tabular}

a Beck Depression Inventory, mild: 10-18; moderate: 19-29.

${ }^{\mathrm{b}} \mathrm{PD}-\mathrm{MCl}$ determined by reanalyzing baseline cognitive scores according to the Movement Disorder

Society Task Force Guidelines. ${ }^{39}$

Psychomotor/attentional composite (Detection Task + Identification Task), executive function composite (Groton Maze Learning Test + Controlled Oral Word Association Test), memory composite (One-Back Task + International Shopping List Task). 
SD, standard deviation; mAIMS, modified Abnormal Involuntary Movements Scale; UPDRS-III, Unified Parkinson's Disease Rating Scale part III; LFADLDS, Lang-Fahn Activities of Daily Living Dyskinesia Scale; PD-MCl, Parkinson's Disease with mild cognitive impairment.

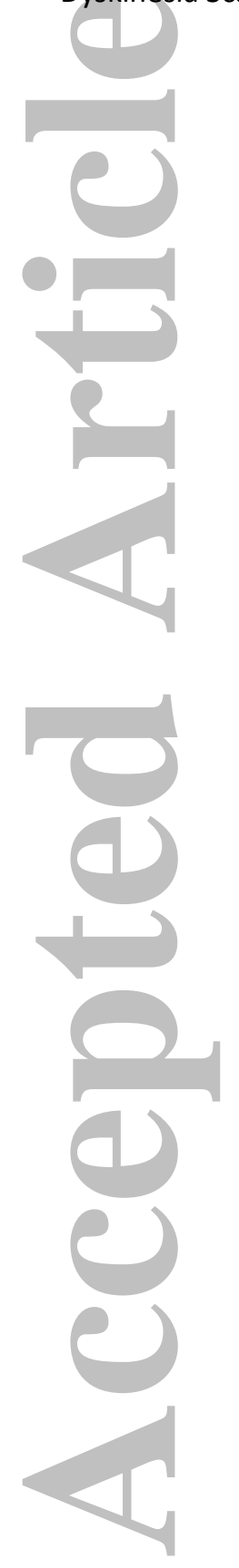

John Wiley \& Sons 
TABLE 2. Analysis of mean change from baseline to day 28 in outcome measures of parkinsonian symptoms and dyskinesia for the per protocol population

\begin{tabular}{|c|c|c|c|}
\hline & \multicolumn{2}{|c|}{ AQW051 } & \multirow{2}{*}{$\begin{array}{l}\text { Placebo } \\
(n=21)\end{array}$} \\
\hline & $10 \mathrm{mg}(\mathrm{n}=23)$ & $50 \mathrm{mg}(\mathrm{n}=19)$ & \\
\hline \multicolumn{4}{|l|}{ mAIMS } \\
\hline LS mean change (SE) & $-3.22(0.85)$ & $-1.92(0.92)$ & $-3.14(0.89)$ \\
\hline Difference vs placebo (SE) & $-0.07(1.24)$ & $1.22(1.28)$ & \\
\hline $95 \% \mathrm{Cl}^{\mathrm{a}}$ & $-2.89,2.75$ & $-1.67,4.12$ & \\
\hline$P$ value ${ }^{\mathrm{a}}$ & 0.997 & 0.534 & \\
\hline \multicolumn{4}{|l|}{ UPDRS-III } \\
\hline LS mean change (SE) & $-1.32(1.28)$ & $-0.44(1.41)$ & $-1.92(1.33)$ \\
\hline Difference vs placebo (SE) & $0.60(1.85)$ & $1.48(1.95)$ & \\
\hline $95 \% \mathrm{Cl}^{\mathrm{a}}$ & $-3.60,4.79$ & $-2.39,5.89$ & \\
\hline$P$ value $^{\mathrm{a}}$ & 0.928 & 0.667 & \\
\hline \multicolumn{4}{|l|}{ UPDRS-IV (items 32-33) } \\
\hline LS mean change (SE) & $-0.95(0.28)$ & $-1.01(0.31)$ & $-1.14(0.29)$ \\
\hline Difference vs placebo (SE) & $0.18(0.41)$ & $0.12(0.43)$ & \\
\hline $95 \% \mathrm{Cl}^{\mathrm{a}}$ & $-0.74,1.10$ & $-0.84,1.09$ & \\
\hline$P$ value & 0.867 & 0.940 & \\
\hline \multicolumn{4}{|l|}{ LFADLDS } \\
\hline LS mean change (SE) & $-0.96(0.57)$ & $-1.73(0.62)$ & $-0.85(0.60)$ \\
\hline Difference vs placebo (SE) & $-0.11(0.83)$ & $-0.88(0.87)$ & \\
\hline $95 \% \mathrm{Cl}^{\mathrm{a}}$ & $-1.98,1.77$ & $-2.84,1.08$ & \\
\hline Pvalue ${ }^{a}$ & 0.987 & 0.494 & \\
\hline \multicolumn{4}{|l|}{${ }^{\mathrm{a} D u n n e t t}$ adjustment. } \\
\hline
\end{tabular}




\section{A Placebo-Controlled Trial of AQW051 in Patients with Moderate to Severe Levodopa-Induced}

\section{Dyskinesia}

Claudia Trenkwalder, ${ }^{1-3}$ Daniela Berg, ${ }^{3,4}$ Olivier Rascol, ${ }^{5,6}$ Karla Eggert, ${ }^{3,7}$ Andres Ceballos-Baumann, ${ }^{3,8}$ Jean-Christophe Corvol, ${ }^{6,9}$ Alexander Storch, ${ }^{3,10}$ Lin Zhang, ${ }^{11}$ Jean-Philippe Azulay, ${ }^{6,12}$ Emmanuel Broussolle, ${ }^{6,13,14}$ Luc Defebvre, ${ }^{6,15}$ Christian Geny, ${ }^{6,16}$ Michal Gostkowski, ${ }^{17}$ Fabrizio Stocchi, ${ }^{18}$ Christine Tranchant, ${ }^{6,19}$ Pascal Derkinderen, ${ }^{6,20}$ Franck Durif, ${ }^{6,21}$ Alberto J. Espay, ${ }^{22}$ Andrew Feigin, ${ }^{23}$ Jean-Luc Houeto, ${ }^{6,24}$ Johannes Schwarz, ${ }^{3,25}$ Thérèse Di Paolo, ${ }^{26,27}$ Dominik Feuerbach, ${ }^{28}$ Hans-Ulrich Hockey, ${ }^{28,29}$ Judith Jaeger, ${ }^{30}$ Annamaria Jakab, ${ }^{28}$ Donald Johns, ${ }^{31}$ Gurutz Linazasoro, ${ }^{32}$ Paul Maruff, ${ }^{33}$ Izabela Rozenberg, ${ }^{28}$ Judit Sovago, ${ }^{28}$ Markus Weiss, ${ }^{28}$ and Baltazar Gomez-Mancilla ${ }^{28,34 *}$

${ }^{1}$ Paracelsus-Elena Hospital, Kassel, Germany

${ }^{2}$ Department of Neurosurgery, University Medical Center, Goettingen, Germany

${ }^{3}$ German Parkinson Study Group

${ }^{4}$ Department of Neurodegeneration, Hertie-Institute for Clinical Brain Research and German Center for Neurodegenerative Diseases, Tübingen, Germany

${ }^{5}$ Department of Clinical Pharmacology and Neurosciences, NeuroToul Excellence Center for Neurodegenerative Disorders, University UPS of Toulouse III, CIC-9302/INSERM UMR825, Hôpital Purpan - Pavillon Riser, Toulouse, France

${ }^{6}$ NS PARK/FCRIN network, France

${ }^{7}$ Department of Neurology, Philipps-University of Marburg, Germany

${ }^{8}$ Schön Klinik München-Schwabing, München, Germany

${ }^{9}$ Sorbonne Universités, UPMC Univ Paris 06, and INSERM UMRS $1127 / C I C-1422$, and CNRS UMR 7225, and AP-HP, and ICM, Hôpital Pitié-Salpêtrière, Département des maladies du système nerveux, Paris, France 
${ }^{10}$ Division of Neurodegenerative Diseases, Department of Neurology, Dresden University of Technology, Dresden, Germany

${ }^{11}$ Department of Neurology, UC Davis MIND Institute, Sacramento, CA, USA

${ }^{12}$ Service de Neurologie et pathologie du Mouvement, Hôpital de la Timone, Marseille Cedex, France

${ }^{13}$ Univisité Lyon 1; Hospices Civils de Lyon, Hôpital Neurologique Pierre Wertheimer, Service de Neurologie C, 69003 Lyon, France

(

${ }^{14}$ CNRS UMR 5229, Centre de Neurosciences Cognitives, Team Basal Ganglia, 69500 Bron, France

${ }^{15}$ Service de Neurologie et Pathologie du movement, EA 1046, CHU de Lille, Hôpital Roger Salengro, Lille, France

${ }^{16}$ Movement to Health (M2H) laboratory, Euromov, University Montpellier 1, Hôpital gui de Chauliac, Montpellier, France

${ }^{17}$ Center for Neurological Restoration, Cleveland Clinic, Cleveland, $\mathrm{OH}$, USA

${ }^{18}$ Department of Neurology, Institute for Research and Medical Care, IROCS, Rome, Italy

${ }^{19}$ Service de Neurologie, Hôpital de Hautepierre, Strasbourg

${ }^{20}$ Centre Investigation Clinique Neurologie, CHU Nantes, Hôpital G\&R Laennec, Nantes, France

${ }^{21}$ Service de Neurologie, Hôpital Gabriel Montpied, Clermont-Ferrand, France

${ }^{22}$ Department of Neurology, James J. and Joan A. Gardner Family Center for Parkinson's Disease and Movement Disorders, University of Cincinnati Academic Health Center, Cincinnati, $\mathrm{OH}$, USA

${ }^{23}$ Feinstein Institute for Medical Research, North Shore - LIJ Health System, Manhasset, NY, USA

${ }^{24}$ Service de Neurologie, CIC-INSERM 1402, CHU de Poitiers, Université de Poitiers, Poitiers, France

${ }^{25}$ Klinik Haag, Haag, Germany

${ }^{26}$ Neuroscience Research Unit, Centre de recherche du CHU de Québec, Québec, Canada 
${ }^{27}$ Faculty of Pharmacy, Laval University, Québec, Canada

${ }^{28}$ Novartis Institutes for BioMedical Research, Basel, Switzerland

${ }^{29}$ Biometrics Matters Ltd, Hamilton, New Zealand

${ }^{30}$ Albert Einstein College of Medicine, NY and CognitionMetrics, LLC, DE, USA

${ }^{31}$ Novartis Pharmaceuticals Corporation, East Hanover, NJ, USA

${ }^{33}$ Inbiomed, San Sebastian, Spain

$\checkmark$

${ }^{31}$ CogState, Inc., New Haven, CT, USA

${ }^{34}$ Department of Neurology and Neurosurgery, McGill University, Montreal, Québec, Canada

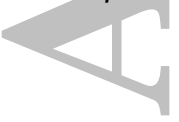

${ }^{*}$ Corresponding author:

$r($

B Gomez-Mancilla, MD PhD

Executive Director, Neuroscience Translational Medicine

Novartis Institutes for BioMedical Research

WSJ.210.25.5

WS

CH-4056 Basel

Car

Switzerland

Tel: +41 61324 0164; Email: baltazar.gomezmancilla@novartis.com

Word count: 1682 (limit = 1700; excluding abstract, acknowledgements, references, figure legends)

Figure/table count: 2 figures/tables (limit $=2$ ) 
Running title: AQW051 in levodopa-induced dyskinesia (character count: 37 inc spaces; limit = 45 letters inc spaces)

Key words: Parkinson's disease; levodopa (L-dopa); nicotinic acetylcholine receptor agonist (nAChR) a7; AQW051; dyskinesias

\section{Funding sources for study:}

This $r$

This research is sponsored by Novartis Pharmaceuticals, Basel, Switzerland, and also in part by the French “Investissement d'Avenir” program (ANR-10-IAIHU-06). Financial support for medical editorial assistance was provided by Novartis Pharmaceuticals, Basel, Switzerland.

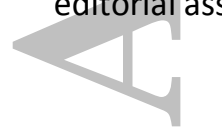

\section{Financial disclosure/conflicts of interest related to research covered in this article:}

Claudia Trenkwalder, Daniela Berg, Olivier Rascol, Karla Eggert, Alexander Storch, and Emmanuel Broussolle have served on advisory boards for Novartis. Claudia Trenkwalder has served on advisory (boar

boards and has received honoraria from Britannia, Mundipharma, UCB and Desitin; has received honoraria from UCB, Desitin Arzneimittel GmbH, and Vifor; and has received grants from Teva, Mundipharma, Michael J. Fox, BmBF, and EU Horizon 2020. Olivier Rascol has served on advisory boards for AbbVie, Addex, Britannia, Lundbeck, Merck, Sanofi-Aventis, Servier, Teva, UCB, XenoPort, and Zambon; received honoraria from AbbVie, Britannia, Lilly France, Lundbeck, Merck, MDS, NeuroDerm, Osmotica, Servier, Teva, UCB, and Zambon; and received grants from Agence Nationale de la Recherche (ANR), CHU de Toulouse, France-Parkinson, INSERM-DHOS Recherche Clinique Translationnelle, Michael J. Fox Foundation, Programme Hospitalier de Recherche Clinique, Boehringer Ingelheim, Lundbeck, Teva, and UCB. Andres Ceballos-Baumann, Jean-Christophe Corvol, Luc Defebvre, and Christian Geny have received honoraria from Novartis. Johannes Schwarz and Gurutz Linazasoro have served as consultants for Novartis and have received honoraria from Novartis; Gurutz Linazasoro has also served on advisory boards for Novartis. Fabrizio Stocchi has 
served on advisory boards and received honoraria from Novartis. Franck Durif has served on advisory boards for Novartis. Thérèse Di Paolo has a collaborative research contract with Novartis Pharma AG for investigating new compounds in vivo, and is also a co-author on patents with ( Novartis Pharma AG. Hans-Ulrich Hockey is an employee of Biometrics Matters Ltd (BML) and served as a contracted statistical consultant to Novartis Pharma AG when working on this article. Paul (a) Maruff is a full-time employee of CogState Ltd, and Judith Jaeger was a full-time employee of CogState Ltd at the time of the study. Annamaria Jakab and Judit Sovago are employees of Novartis Cogstate Pharma AG. Baltazar Gomez-Mancilla, Dominik Feuerbach, Izabela Rozenberg, and Markus Weiss are employees of, and hold shares in, Novartis Pharma AG; Markus Weiss is also a Novartis patent holder. Donald Johns was a full-time employee of Novartis at the time of the study. Alberto Espay, Lin Zhang, Jean-Philippe Azulay, Michal Gostkowski, Christine Tranchant, Pascal Derkinderen, Andrew Feigin, and Jean-Luc Houeto have declared no financial conflicts of interest related to research covered in this article.

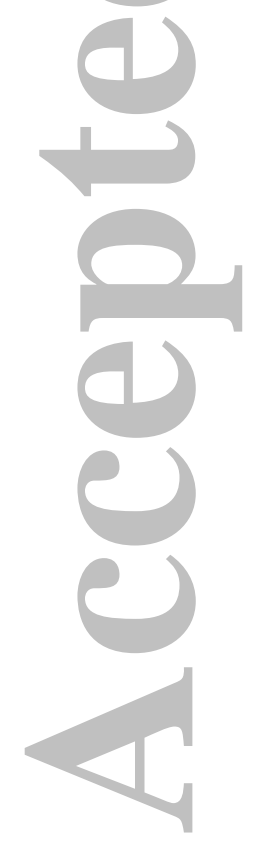




\section{Abstract [Word count: $146(\max 150)]$}

\section{Introduction}

This Phase II, randomized, double-blind, placebo-controlled study evaluated the efficacy and safety of the nicotinic acetylcholine receptor $\alpha 7$ agonist, AQW051, in patients with Parkinson's disease and levodopa-induced dyskinesia.

\section{Methods}

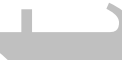

Patients with idiopathic Parkinson's disease and moderate to severe levodopa-induced dyskinesia were randomized to AQW051 $10 \mathrm{mg}(n=24)$, AQW051 $50 \mathrm{mg}(\mathrm{n}=24)$, or placebo $(n=23)$ once daily for 28 days. Co-primary endpoints were change in Modified Abnormal Involuntary Movement Scale and Unified Parkinson's Disease Rating Scale part III scores. Secondary outcomes included pharmacokinetics.

\section{Conclusions}

AQW051 did not significantly reduce dyskinesia or parkinsonian severity. 


\section{Introduction}

Motor complications such as levodopa (L-dopa)-induced dyskinesia (LID) negatively impact the lives of patients with Parkinson's disease (PD), ${ }^{1-3}$ and there are few sustained, non-invasive treatments for LID that do not reduce the antiparkinsonian benefits of L-dopa. Amantadine is currently the sole medication available and recommended for the management of LID. ${ }^{4}$ However, not all patients respond to or tolerate amantadine, and the prescription of amantadine is restricted by regulatory guidance in some countries (e.g. in Germany ${ }^{5}$ ).

Nicotine has been shown to protect against or alleviate nigrostriatal damage ${ }^{6-11}$ and improve LID $^{12-14}$ in parkinsonian animal models. The antidyskinetic and neuroprotective effects of nicotine are exerted via multiple nicotinic acetylcholine receptors (nAChRs). ${ }^{6,10,12,13,15-17}$ The antidyskinetic potential of $\alpha 7 \mathrm{nAChR}$ agonists has now been displayed in vivo using the novel, selective partial agonist, (R)-3-(6-p-Tolyl-pyridin-3-yloxy)-1-aza-bicyclo(2.2.2)octane (AQW051). ${ }^{18}$ AQW051 significantly reduced dyskinesia in 1-methyl-4-phenyl-1,2,3,6-tetrahydropyridine (MPTP)-lesioned monkeys without compromising the benefits of L-dopa. ${ }^{19}$ The objective of the current study was to evaluate the efficacy and safety of AQW051 in patients with moderate to severe PD-LID. As preclinical and clinical evidence suggests that $\alpha 7$ nAChR agonists, including AQW051, can also improve cognition, ${ }^{20-32}$ AQW051 was also evaluated for pro-cognitive effects in a post-hoc exploratory analysis.

\section{Methods}

This was a Phase II, multicenter, randomized, double-blind, parallel-group, placebo-controlled multidose study in PD-LID. Eligible patients were non-smoking men and women, aged 30-85 years, with idiopathic PD as per the UK Parkinson's Disease Society Brain Bank criteria. Patients were required to have: LID >20\% (Unified Parkinson's Disease Rating Scale [UPDRS] item 32 rating $\geq 1$ ) of moderate to severe intensity (UPDRS item 33 rating $\geq 2$ ) ${ }^{33}$ LID for $\geq 3$ months before randomization; received L-dopa for $\geq 3$ years; stable treatment with L-dopa for $\geq 1$ month before randomization. Other 
concomitant antiparkinsonian medication was allowed if treatment was stable for $\geq 1$ month prior to randomization. Treatment with amantadine, antidepressants (except strong cytochrome [CYP]1A2 and CYP3A4 inhibitors), and/or benzodiazepines were permitted provided the dosing regimen was stable for $\geq 1$ month before randomization.

Patients were randomized at a ratio of 1:1:1 into one of three treatment groups: AQW051 $50 \mathrm{mg}$, AQW051 $10 \mathrm{mg}$, or placebo. Treatment was administered orally, once daily in the morning after the initial L-dopa dose, for a period of 28 days, with a 2-week follow-up. Assessments were performed every week, once during follow-up, and at the end of study visit.

The protocol and amendments were approved by the Independent Ethics Committee and Institutional Review Board at each study center. This study was conducted according to the ethical principles of the Declaration of Helsinki and was registered on ClinicalTrials.gov (identifier NCT01474421). Informed written consent was obtained from all patients.

\section{Outcomes}

The co-primary outcome measures were the Modified Abnormal Involuntary Movement Scale $(\text { mAIMS) })^{34}$ and UPDRS-III items $18-31,{ }^{35}$ respectively. Assessments were performed in the morning 1 $\mathrm{h}$ post L-dopa dose during ON-time and in the afternoon at a patient-specific time point.

Secondary outcome measures included: UPDRS-IV items 32-33, Lang-Fahn Activities of Daily Living and Dyskinesia Scale (LFADLDS) sum score, ${ }^{36}$ and a cognitive test battery (CogState) ${ }^{37}$ for safety analysis and for tracking potential pro-cognitive effects.

\section{Pharmacokinetics}

Blood samples ( $3 \mathrm{~mL}$ ) were collected into EDTA-containing tubes according to a predefined schedule. Sampling took place pre-dose and on days $1,8,16,21$, and $28 ; 1,3,4,5,8$, and $12 \mathrm{~h}$ post-dose on day 28; and before and after the assessments on day 32. Plasma concentrations of AQW051 were 
quantified using a validated liquid chromatography tandem mass spectrometry method (HPLC-

MS/MS). The lower limit of quantification was $0.050 \mathrm{ng} / \mathrm{mL}$ using $0.200 \mathrm{~mL}$ of plasma.

\section{Safety}

Assessments included adverse events (AEs) and serious AEs (SAEs) reporting, laboratory tests, vital signs, electrocardiograms, and use of the Columbia-Suicidality Severity Rating Scale (C-SSRS).

\section{Statistical analysis}

Stati

Descriptive statistics were used to summarize AEs, safety, and demographic variables for the safety population (all patients who received $\geq 1$ dose of study drug). Analysis of covariance of change from baseline of the per protocol population (all patients with $\geq 1$ post-randomization efficacy assessment and no protocol deviations nor withdrawn) was the primary analysis, with relevant baseline values as the covariate and treatment group as a fixed factor. The effect over placebo was estimated for each AQW051 dose using a Dunnett adjustment, and there were no corrections for multiple comparisons between variables.

The pharmacokinetic parameters at steady state: maximum plasma concentration $\left(C_{\max }\right)$, time to maximum plasma concentration $\left(\mathrm{T}_{\max }\right)$, area under the curve for $0-24 \mathrm{~h}\left(\mathrm{AUC}_{0-24 h}\right)$, and oral clearance (CL/F) were determined using non-compartmental methods and summarized by dose group using descriptive statistics for the PK population (all patients with valid PK data).

\section{Results}

Seventy-one patients were randomized to receive AQW051 $10 \mathrm{mg}(\mathrm{n}=24)$, AQW051 $50 \mathrm{mg}(\mathrm{n}=24)$, or placebo $(n=23) ; 67$ patients completed the study and 63 did so without protocol deviations. Patient demographics and clinical variables for the safety population are summarized in Table 1. Efficacy 
The study did not meet its primary endpoints, with change in mean sum score for mAIMS and UPDRS-III showing no significant improvements in LID or parkinsonian symptoms following AQW051 treatment at either dose (Table 2).

\section{Cognitive function}

In the primary analysis, AQW051 was not associated with statistically significant improvements in cognitive outcomes. However, exploratory repeated measures analysis of the safety population showed that compared with placebo, AQW051 $50 \mathrm{mg} /$ day yielded a change corresponding to a standardized effect size of $0.5(P=0.024)$ in the CogState memory composite scores and an effect size of $0.4(P=0.073)$ was seen for AQW051 $10 \mathrm{mg} /$ day. The individual memory tasks included in the memory composite (One-Back Task [ONB] + International Shopping List Task [ISL]) also improved moderately at both AQW051 doses, with improvements in the ISL at AQW051 $50 \mathrm{mg} /$ day reaching significance $(P=0.048)$.

\section{Pharmacokinetics}

Comparison of pre-dose plasma concentrations of AQW051 indicates steady state was reached within the first week of dosing. At day $28, \mathrm{~T}_{\max }$ median (range) values were very similar for 10 and $50 \mathrm{mg} /$ day; $5.00 \mathrm{~h}$ (2.92-11.9) and $4.99 \mathrm{~h}$ (3-8), respectively. Mean (SD) CL/F values were 88.8 (68.4) L/h and 102 (59.2) L/h at 10 and $50 \mathrm{mg} /$ day, respectively. Exposure in terms of $\mathrm{AUC}_{0-24 \mathrm{~h}}$ and $\mathrm{C}_{\max }$ increased $4.3(160-686 \mathrm{ng} * \mathrm{~h} / \mathrm{mL})$ and 4.5 -fold $(8.62-38.7 \mathrm{ng} / \mathrm{mL})$, respectively, with a 5 -fold increase of dose from 10 to $50 \mathrm{mg}$ suggesting dose proportionality in systemic exposure across the dose range for AQW051.

\section{Safety}

AEs were experienced by 18 patients receiving AQW051 10 mg/day, 15 receiving AQW051 $50 \mathrm{mg} /$ day, and 18 receiving placebo. They were mostly mild to moderate, with dyskinesia the most frequently reported $\mathrm{AE}$ across all treatment groups $(4.2 \%, 25.0 \%$, and $13.0 \%$ of patients in the $10 \mathrm{mg} /$ day, $50 \mathrm{mg} /$ day, and placebo groups, respectively). Nausea $(20.8 \%, 4.2 \%$, and $0 \%$, 
respectively), falls $(8.3 \%, 12.5 \%$, and $4.3 \%$, respectively) and fatigue $(8.3 \%, 8.3 \%$, and $8.7 \%$, respectively) were the next most commonly reported AEs overall after dyskinesia.

Two patients receiving AQW051 $50 \mathrm{mg} /$ day experienced SAEs (one case each of mild ON-OFF phenomenon and severe neuroborreliosis). These were not considered to be treatment-related by the investigators and no action regarding study medication was taken. In both cases the event had resolved on follow-up. Two patients experienced AEs that the investigators considered treatmentrelated and resulted in their withdrawal from the study. One patient reported worsening dyskinesia on day 2 after treatment with AQW051 $50 \mathrm{mg} /$ day; the dyskinesia was ongoing at the last follow-up on day 21 , and no further follow-ups have been reported. The second patient (with an active history of depression) reported mild depression on day 11 of treatment with AQW051 $10 \mathrm{mg} /$ day. Her depression had resolved when followed up 12 months later.

\section{Discussion}

AQW051 treatment did not significantly improve dyskinesia or parkinsonian symptoms when using the primary endpoint of change in mAIMS or UPDRS-III scores. Our findings contrast with the current understanding of nicotinic receptor function in the basal ganglia, and preclinical efficacy of AQW051 in the LID primate model. ${ }^{19}$ This forces us to reconsider the hypothesis of targeting the alpha7 nicotinic receptors to suppress LID in humans. However, a variety of factors may explain these negative results without invalidating the concept, such as a sub-therapeutic dosing of AQW051 for PD-LID; a lack of sensitivity of mAIMS in measuring treatment-related changes in PD-LID; ${ }^{38}$ or a low comparability between groups for exposure to amantadine and potential effect on response to AQW051. The significant variability of dyskinesia among patients should not be overlooked as a reason for the study not meeting its primary endpoints, as biphasic dyskinesias were not separately reported in this study and may have different pathological mechanisms and pharmacological responses than peak-dose LIDs. 
A possible benefit for AQW051 in cognition was observed following a post-hoc exploratory analysis. Moderate treatment effects were observed on memory tasks of consistent magnitude and several differences to placebo were statistically significant. These exploratory results are supported by the preclinical cognitive-enhancing potential of AQW051 and other nAChR alpha7 agonists, ${ }^{20-28}$ and clinical findings in healthy male subjects ${ }^{29}$ and patients with schizophrenia. ${ }^{30-32}$ These findings reinforce the concept that neuropsychological and behavioral assessments should be considered as part of future studies evaluating these compounds.

AQW051 was well tolerated and the majority of AEs were mild to moderate in severity. AQW051 did A not cause any psychiatric AEs in patients with advanced PD who are known to be at high risk for developing these side effects with various drugs. This observation might echo some positive signals discussed previously, although the limited size of the sample and short duration of follow-up prevent any firm conclusion. The higher incidence of dyskinesia as an AE within the $50 \mathrm{mg}$ AQW051 group was unexpected. This might be related to some disparity between the treatment groups that occurred by chance at randomization. Patients in the $50 \mathrm{mg}$ AQW051 group received higher mean daily doses of L-dopa and were more frequently exposed to amantadine, with the risk of potential unknown pharmacodynamic drug interactions.

In conclusion, AQW051 did not significantly reduce dyskinesia or parkinsonian severity when using the primary endpoints of change in mAIMS and UPDRS. Further effects of this drug need to be explored with more specific trial designs and larger patient populations. 


\section{Acknowledgments}

We wish to thank the following investigators: S. Arguillère, I. Benatru, A.M. Bonnet, T. Boraud, K. Brockmann, M. Canelo, M. Charif, B. Debilly, K. Dujardin, U. Fietzek, A. Fradet, M. Galitzky, J. Godau, A.E. Haraszti, O. Lagha-Boukbiza, N. Longato, A. Noda, C. Nölker, C. Oehlwein, H. Pape, F. Pineau, T. Rouaud, I. Roullet Solignac, F. Tison, L. Vacca, D. Vadasz, B. Wieder, and T. Witjas; we also thank the following nurses and research technicians: F. Evano, M. France Le Labousse, P. Marc, L. Marquine, and C. Souyris, for their support during the study. We are grateful to the administrative support provided by N. Barun, S. Bernard, V. Chaigneau, E. Dellapina, M. Gaboreau, P. Gauteul, C. Hourquin, S. Ledily, E. Rabois, and C. Rouges, who helped co-ordinate the study as part of the French NS PARK network. We wish to thank Dr Martina Müngersdorf and Dr Christian Oehlwein for their involvement in the early development of this manuscript. We also thank Georgina Collett, PhD, of iMed Comms, an Ashfield Company, part of UDG Healthcare plc (funded by Novartis Pharmaceuticals, Basel, Switzerland) for medical editorial assistance with this manuscript. We thank the patients who participated in this study.

\section{Author roles in manuscript}

Conception and design of study: Baltazar Gomez-Mancilla, Thérèse Di Paolo, Dominik Feuerbach, Markus Weiss, Paul Maruff, Donald Johns

Acquisition, analysis, and interpretation of data: Baltazar Gomez-Mancilla, Claudia Trenkwalder, Olivier Rascol, Karla Eggert, Andrew Feigin, Paul Maruff (specifically, cognition readouts), Annamaria Jakab (specifically, bioanalytical quantification of PK samples), Alberto Espay, Donald Johns, Fabrizio Stocchi

Acquisition of data: Claudia Trenkwalder, Daniela Berg, Andres Ceballos-Baumann, Jean-Christophe Corvol, Alexander Storch, Lin Zhang, Emmanuel Broussolle, Christian Geny, Michal Gostkowski, Johannes Schwarz, Izabela Rozenberg, Jean-Philippe Azulay, Christine Tranchant, Pascal Derkinderen, Franck Durif, Jean-Luc Houeto 
Analysis and interpretation of data: Luc Defebvre, Hans-Ulrich Hockey, Gurutz Linazasoro, Judit Sovago, Markus Weiss (PK data)

Statistical expertise: Baltazar Gomez-Mancilla, Hans-Ulrich Hockey, Paul Maruff

Drafting of all or part of the manuscript: Baltazar Gomez-Mancilla, Claudia Trenkwalder, Thérèse Di Paolo, Dominik Feuerbach, Annamaria Jakab, Paul Maruff, Donald Johns

Critical revision of manuscript for important intellectual content: Baltazar Gomez-Mancilla, Claudia Trenkwalder, Daniela Berg, Olivier Rascol, Karla Eggert, Andres Ceballos-Baumann, Jean-Christophe Corvol, Alexander Storch, Lin Zhang, Emmanuel Broussolle, Luc Defebvre, Michal Gostkowski, Andrew Feigin, Johannes Schwarz, Thérèse Di Paolo, Hans-Ulrich Hockey, Judith Jaeger, Annamaria Jakab, Paul Maruff, Gurutz Linazasoro, Izabela Rozenberg, Judit Sovago, Markus Weiss, Jean-Philippe Azulay, Dominik Feuerbach, Christine Tranchant, Pascal Derkinderen, Frank Durif, Alberto Espay, Jean-Luc Houeto, Fabrizio Stocchi

Proofreading: Hans-Ulrich Hockey

Administrative, technical, or material support: Baltazar Gomez-Mancilla, Claudia Trenkwalder, Daniela Berg, Karla Eggert, Andres Ceballos-Baumann, Emmanuel Broussolle, Judith Jaeger, Gurutz Linazasoro, Paul Maruff, Izabela Rozenberg, Judit Sovago, Jean-Luc Houeto, Donald Johns Supervision: Baltazar Gomez-Mancilla, Donald Johns, Claudia Trenkwalder, Johannes Schwarz, Annamaria Jakab, Jean-Philippe Azulay, Dominik Feuerbach, Franck Durif, Fabrizio Stocchi Obtaining funding: Baltazar Gomez-Mancilla, Donald Johns, Dominik Feuerbach

\section{Full financial disclosures of all authors for the past year}

Claudia Trenkwalder has served on advisory boards for Mundipharma, Britannia Pharma, UCB and Novartis; has received honoraria from UCB, Desitin Arzneimittel GmbH, and Vifor; and has received grants from Teva, Mundipharma, Michael J. Fox, BmBF, and EU Horizon 2020. Daniela Berg has served on advisory boards for Novartis and UCB Pharma GmbH; has received speaker honoraria from 
Lundbeck, Teva, and UCB Pharma GmbH; and has received grants from Michael J. Fox Foundation, BmBF (German Federal Ministry of Education and Research), dPV (German Parkinson's Association), Internationale Parkinson Fonds Deutschland GmbH, Janssen Pharmaceutica, Teva Pharma GmbH, and UCB Pharma GmbH. Olivier Rascol has served on advisory boards for AbbVie, Addex, Britannia, Lundbeck, Merck, Sanofi-Aventis, Servier, Teva, UCB, XenoPort, and Zambon; received honoraria from AbbVie, Britannia, Lilly France, Lundbeck, Merck, MDS, NeuroDerm, Osmotica, Servier, Teva, UCB, and Zambon; and received grants from Agence Nationale de la Recherche (ANR), CHU de Toulouse, France-Parkinson, INSERM-DHOS Recherche Clinique Translationnelle, Michael J. Fox Foundation, Programme Hospitalier de Recherche Clinique, Boehringer Ingelheim, Lundbeck, Teva, and UCB. Karla Eggert has served as a consultant for Desitin Arzneimittel GmbH, Novartis, Zambon, Solvay Pharmaceuticals, and UCB; served on advisory boards for Medtronic, Merck Sharp \& Dohme, Novartis, Zambon, and UCB; received honoraria from Abbott Arzneimittel GmbH, Boehringer Ingelheim, Desitin Arzneimittel GmbH, Meda Pharma, Novartis, Zambon, Teva, and UCB; and received scientific grants from the German Ministry of Education and Health, and the Pitzer Foundation. Andres Ceballos-Baumann has served on advisory boards for AbbVie, Archimedes, Desitin Arzneimittel GmbH, Ipsen, Licher MT, Merz Pharmaceuticals, Meda, Medtronic, and UCB; received honoraria from AbbVie, Allergan, Archimedes, BIAL, Bioprojet, Desitin Arzneimittel GmbH, Ipsen, Licher MT, Meda, Merz Pharmaceuticals, Medtronic, Neurosearch, Novartis, Teva, and UCB; and received research grants from Deutsche Parkinson Vereinigung e.V., Verein zur Förderung de Behandlung und Betreuung neurologisch Kranker e.V., and Deutsche Stiftung Neurologie. JeanChristophe Corvol has stock ownership in B\&A Therapeutics; partnerships with Sanofi-Aventis; received honoraria from BIAL and Novartis; and received research grants from Michael J. Fox Foundation, Programme Hospitalier de Recherche Clinique, Agence Nationale pour la recherché (ANR), Innovative Medicine Initiative (IMI), and travel grants from Teva and UCB. Alexander Storch is employed by the non-profit federal government organizations, Dresden University of Technology, University Clinics, and German Center for Neurodegenerative Diseases (DZNE); has served as a 
consultant for Britannia, GKC Melbourne, and Mundipharma; served on advisory boards for AbbVie, Desitin, Elblandkliniken Meissen, GlaxoSmithKline, Klinik Tharandter Wald, Klinikum Dessau, MEDA Pharma, Medtronic, Mundipharma, Teva, and UCB; and received research grants from GKC, Teva (unrestricted clinical study grants), German Federal Ministry of Education and Research, German Federal Ministry of Economy, German Research Association (DFG), Helmholtz Association Germany (through DZNE), NCL Foundation, NA Advocacy, and the International Parkinson Foundation (all research grants, non-profit organizations). Jean-Philippe Azulay has served as a consultant for, and on advisory boards for, AbbVie, Lundbeck, Medtronic, Novartis, Teva, and UCB. Emmanuel Broussolle has served on advisory boards for AbbVie, Lundbeck, Novartis, Teva, and UCB, and received travel funding from Novartis, Teva, and UCB. Luc Defebvre has served as a consultant to AbbVie, and received honoraria from Novartis and Teva. Christian Geny has served on advisory boards and received honoraria from Novartis. Fabrizio Stocchi has served on advisory boards, acted as a consultant and received honoraria from Chiesi, GlaxoSmithKline, Lundbeck, IMPAX, Merck, Novartis, Teva, UCB, and Zanbon. He has also served on an advisory board and received honoraria from Britannia. Christine Tranchant has served on advisory boards for Allergan and acted as a consultant for Teva. Pascal Derkinderen has received grant support from Michael J. Fox Foundation. Franck Durif has served on advisory boards for AbbVie, Allergan, Lundbeck, Novartis, and Teva, and has a contract with Lundbeck. He has received grant support from Association France Parkinson, Fédération de Recherché pour le Cerveau, Fondation de l'Avenir, and the French Ministry of Health. Alberto Espay is supported by the National Institute of Health [NIH] (K23MH092735) and has received grant support from CleveMed/Great Lakes Neurotechnologies, Davis Phinney Foundation, and Michael J. Fox Foundation; personal compensation as a consultant/scientific advisory board member for Solvay, Abbott, Chelsea Therapeutics, Teva, Impax, Merz, Lundbeck, and Eli Lilly; and honoraria from TEVA, UCB, the American Academy of Neurology, and the Movement Disorders Society; and publishing royalties from Lippincott Williams \& Wilkins and Cambridge University Press. Andrew Feigin has served as a consultant to Third Rock Ventures and Vaccinex, Inc., and received 
grants from National Institute of Neurological Disorders and Stroke (NINDS). Jean-Luc Houeto has served as a consultant for Abbott, AbbVie, Lundbeck-Teva, and UCB and participated in advisory boards for AbbVie, Lundbeck, and Novartis. Johannes Schwarz has served as a consultant for Boehringer Ingelheim, Desitin Arzneimittel GmbH, Novartis, and UCB, and received honoraria from

AbbVie, Boehringer Ingelheim, Desitin Arzneimittel GmbH, Licher MT GmbH, Novartis, and UCB. Thérèse Di Paolo has served as a consultant to Biotic; received grants from the Canadian Institutes of Health Research (CIHR), Quebec Consortium for Drug Discovery (CQDM), and Natural Sciences and Engineering Research Council of Canada (NSERC); has collaborative research contracts with Novartis Pharma AG and Prexton Therapeutics for investigating new compounds in vivo; and is a co-author on patents with Novartis Pharma AG. Gurutz Linazasoro has served as a consultant to, received honoraria from, and served on advisory boards for Novartis. Hans-Ulrich Hockey is an employee of Biometrics Matters Ltd (BML) and is serving as a contracted statistical consultant to Auckland Hospital Board, Fisher and Paykel Healthcare, Manuka Health, and Novartis Pharma AG. Paul Maruff is a full-time employee of CogState Ltd. Judith Jaeger was a full-time employee at CogState Ltd at the time of the study. She is now President and Principal Scientist at CognitionMetrics, LLC. Annamaria Jakab and Judit Sovago are employees of Novartis Pharma AG. Baltazar Gomez-Mancilla, Dominik Feuerbach, Izabela Rozenberg, and Markus Weiss are employees of, and hold shares in, Novartis Pharma AG; Markus Weiss is also a Novartis patent holder. Donald Johns was a full-time employee of Novartis at the time of the study. He is now a full-time employee of, and holds shares in, Biogen. Michal Gostkowski and Lin Zhang have declared no financial interests for the previous 12 months. 


\section{References}

1. Fabbrini G, Brotchie JM, Grandas F, Nomoto M, Goetz CG. Levodopa-induced dyskinesias. Mov Disord 2007;22:1379-1389.

2. Ahlskog JE, Muenter MD. Frequency of levodopa-related dyskinesias and motor fluctuations as estimated from the cumulative literature. Mov Disord 2001;16:448-458.

3. Chapuis S, Ouchchane L, Metz O, Gerbaud L, Durif F. Impact of the motor complications of Parkinson's disease on the quality of life. Mov Disord 2005;20:224-230.

4. Seppi K, Weintraub D, Coelho M, et al. The Movement Disorder Society Evidence-Based Medicine Review Update: treatments for the non-motor symptoms of Parkinson's disease. Mov Disord 2011;26(Suppl 3):S42-S80.

5. ratiopharm $\mathrm{GmbH}$. Amantadin-ratiopharm $100 \mathrm{mg}$ Filmtabletten [in German]. Ulm, ratiopharm, 2010.

6. Huang LZ, Parameswaran N, Bordia T, Michael MJ, Quik M. Nicotine is neuroprotective when administered before but not after nigrostriatal damage in rats and monkeys. J Neurochem 2009;109:826-837.

7. Parain K, Marchand V, Dumery B, Hirsch E. Nicotine, but not cotinine, partially protects dopaminergic neurons against MPTP-induced degeneration in mice. Brain Res 2001;890:347350.

8. Quik M, Chen L, Parameswaran N, Xie X, Langston JW, McCallum SE. Chronic oral nicotine normalizes dopaminergic function and synaptic plasticity in 1-methyl-4-phenyl-1,2,3,6tetrahydropyridine-lesioned primates. J Neurosci 2006;26:4681-4689. 
9. Quik M, Parameswaran N, McCallum SE, et al. Chronic oral nicotine treatment protects against striatal degeneration in MPTP-treated primates. J Neurochem 2006;98:1866-1875.

10. Ryan RE, Ross SA, Drago J, Loiacono RE. Dose-related neuroprotective effects of chronic nicotine in 6-hydroxydopamine treated rats, and loss of neuroprotection in alpha4 nicotinic receptor subunit knockout mice. Br J Pharmacol 2001;132:1650-1656.

11. Visanji NP, O'Neill MJ, Duty S. Nicotine, but neither the alpha4beta2 ligand RJR2403 nor an alpha7 nAChR subtype selective agonist, protects against a partial 6-hydroxydopamine lesion of the rat median forebrain bundle. Neuropharmacology 2006;51:506-516.

12. Bordia T, Campos C, Huang L, Quik M. Continuous and intermittent nicotine treatment reduces L-3,4-dihydroxyphenylalanine (L-DOPA)-induced dyskinesias in a rat model of Parkinson's disease. J Pharmacol Exp Ther 2008;327:239-247.

13. Huang LZ, Campos C, Ly J, Ivy Carroll F, Quik M. Nicotinic receptor agonists decrease L-dopainduced dyskinesias most effectively in partially lesioned parkinsonian rats.

Neuropharmacology 2011;60:861-868.

14. Quik M, Cox H, Parameswaran N, O'Leary K, Langston JW, Di Monte D. Nicotine reduces levodopa-induced dyskinesias in lesioned monkeys. Ann Neurol 2007;62:588-596.

15. Stuckenholz V, Bacher M, Balzer-Geldsetzer M, et al. The alpha7 nAChR agonist PNU-282987 reduces inflammation and MPTP-induced nigral dopaminergic cell loss in mice. J Parkinsons Dis 2013;3:161-172.

16. Suzuki S, Kawamata J, Matsushita T, et al. 3-[(2,4-Dimethoxy)benzylidene]-anabaseine dihydrochloride protects against 6-hydroxydopamine-induced parkinsonian neurodegeneration through alpha7 nicotinic acetylcholine receptor stimulation in rats. J Neurosci Res 2013;91:462-471. 
17. Zhang D, Mallela A, Sohn D, et al. Nicotinic receptor agonists reduce L-DOPA-induced dyskinesias in a monkey model of Parkinson's disease. J Pharmacol Exp Ther 2013;347:225234.

18. Hurth K, Gomez-Mancilla B, Hoyer D, et al. Identification of AQW051, an alpha7 nicotinic acetylcholine receptor partial agonist for the treatment of cognitive impairment associated with schizophrenia. Abstract MEDI 222 at the Division of Medicinal Chemistry, 247th American Chemical Society (ACS) National Meeting, Dallas, Texas, USA, March 16-20, 2014.

19. Di Paolo T, Gregoire L, Feuerbach D, Elbast W, Weiss M, Gomez-Mancilla B. AQW051, a novel and selective nicotinic acetylcholine receptor $\alpha 7$ partial agonist, reduces L-Dopa-induced dyskinesias and extends the duration of L-Dopa effects in parkinsonian monkeys. Parkinsonism Relat Disord 2014;20:1119-1123.

20. Feuerbach D, Pezous N, Weiss M, Shakeri-Nejad K, Lingenhoehl K, Hoyer D, Hurth K, Bilbe G, Pryce CR, McAllister K, Chaperon F, Kucher K, Johns D, Blaettler T, Lopez Lopez C. AQW051, a novel, potent and selective $\alpha 7$ nicotinic ACh receptor partial agonist: pharmacological characterization and phase I evaluation. Br J Pharmacol. 2015;172:1292-304.

21. de Fiebre CM, Meyer EM, Henry JC, Muraskin SI, Kem WR, Papke RL. Characterization of a series of anabaseine-derived compounds reveals that the 3-(4)-dimethylaminocinnamylidine derivative is a selective agonist at neuronal nicotinic alpha 7/125I-alpha-bungarotoxin receptor subtypes. Mol Pharmacol 1995;47:164-171.

22. Feuerbach D, Nozulak J, Lingenhoehl K, McAllister K, Hoyer D. JN403, in vitro characterization of a novel nicotinic acetylcholine receptor alpha7 selective agonist. Neurosci Lett 2007;416:61-65. 
23. Feuerbach $D$, Lingenhoehl $K$, Olpe HR, et al. The selective nicotinic acetylcholine receptor alpha7 agonist JN403 is active in animal models of cognition, sensory gating, epilepsy and pain. Neuropharmacology 2009;56:254-263.

24. Hajos M, Hurst RS, Hoffmann WE, et al. The selective alpha7 nicotinic acetylcholine receptor agonist PNU-282987 [N-[(3R)-1-Azabicyclo[2.2.2]oct-3-yl]-4-chlorobenzamide hydrochloride] enhances GABAergic synaptic activity in brain slices and restores auditory gating deficits in anesthetized rats. J Pharmacol Exp Ther 2005;312:1213-1222.

25. Bitner R, Anderson D, Drescher K, et al. Preclinical characterization of a selective alpha-7 neuronal nicotinic acetylcholine receptor agonist ABT-126: a novel therapeutic agent for the treatment of cognitive impairment in Alzheimer's disease and schizophrenia. Alzheimers Dement 2013;9:P817-P818.

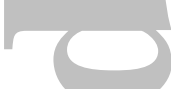

26. Hauser TA, Kucinski A, Jordan KG, et al. TC-5619: an alpha7 neuronal nicotinic receptorselective agonist that demonstrates efficacy in animal models of the positive and negative 1 symptoms and cognitive dysfunction of schizophrenia. Biochem Pharmacol 2009;78:803-812.

27. Mazurov AA, Kombo DC, Hauser TA, et al. Discovery of (2S,3R)-N-[2-(pyridin-3-ylmethyl)-1azabicyclo[2.2.2]oct-3-yl]benzo[b]furan-2-car boxamide (TC-5619), a selective alpha7 nicotinic acetylcholine receptor agonist, for the treatment of cognitive disorders. J Med Chem 2012;55:9793-9809.

27. Prickaerts J, van Goethem NP, Chesworth R, et al. EVP-6124, a novel and selective alpha7 nicotinic acetylcholine receptor partial agonist, improves memory performance by potentiating the acetylcholine response of alpha7 nicotinic acetylcholine receptors. Neuropharmacology 2012;62:1099-1110. 
29. Kitagawa H, Takenouchi T, Azuma R, et al. Safety, pharmacokinetics, and effects on cognitive function of multiple doses of GTS-21 in healthy, male volunteers. Neuropsychopharmacology 2003;28:542-551.

30. Olincy A, Harris JG, Johnson LL, et al. Proof-of-concept trial of an alpha7 nicotinic agonist in schizophrenia. Arch Gen Psychiatry 2006;63:630-638.

31. Lieberman JA, Dunbar G, Segreti AC, et al. A randomized exploratory trial of an alpha-7 nicotinic receptor agonist (TC-5619) for cognitive enhancement in schizophrenia.

Neuropsychopharmacology 2013;38:968-975.

32. Preskorn SH, Gawryl M, Dgetluck N, Palfreyman M, Bauer LO, Hilt DC. Normalizing effects of EVP-6124, an alpha-7 nicotinic partial agonist, on event-related potentials and cognition: a proof of concept, randomized trial in patients with schizophrenia. J Psychiatr Pract 2014;20:12-24.

33. Fahn S, Elton R, Members of the UPDRS Development Committee. Unified Parkinson's Disease Rating Scale. In: Fahn S, Marsden CD, Calne DB, Goldstein M. Eds. Recent developments in Parkinson's disease. Florham Park, NJ, Macmillan Healthcare Information, 1987; 153-164.

34. Guy W. Assessment Manual for Psychopharmacology: Revised (DHEW publication no. ADM 76338). Rockville, MD, US Department of Health, Education and Welfare; Public Health Service; Alcohol, Drug Abuse and Mental Health Administration; NIMH Psychopharmacology Research Branch; Division of Extramural Research Programs, 1976.

35. Marconi R, Lefebvre-Caparros D, Bonnet AM, Vidailhet M, Dubois B, Agid Y. Levodopa-induced dyskinesias in Parkinson's disease phenomenology and pathophysiology. Mov Disord 1994;9:2-12. 
36. Parkinson Study Group. Evaluation of dyskinesias in a pilot, randomized, placebo-controlled trial of remacemide in advanced Parkinson disease. Arch Neurol 2001;58:1660-1668.

37. Falleti MG, Maruff P, Collie A, Darby DG. Practice effects associated with the repeated assessment of cognitive function using the CogState battery at 10-minute, one week and one month test-retest intervals. J Clin Exp Neuropsychol 2006;28:1095-1112.

38. Goetz CG, Stebbins GT, Chung KA, et al. Which dyskinesia scale best detects treatment response? Mov Disord 2013;28:341-346.

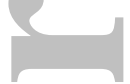

39. Litvan I, Goldman JG, Troster Al, et al. Diagnostic criteria for mild cognitive impairment in Parkin Parkinson's disease: Movement Disorder Society Task Force guidelines. Mov Disord 2012;27:349-356.

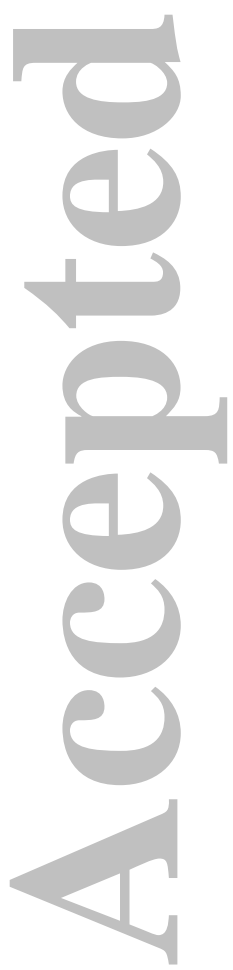




\section{University Library}

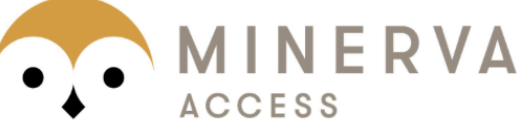

A gateway to Melbourne's research publications

Minerva Access is the Institutional Repository of The University of Melbourne

\section{Author/s:}

Trenkwalder, C;Berg, D;Rascol, O;Eggert, K;Ceballos-Baumann, A;Corvol, J-C;Storch, A;Zhang, L;Azulay, J-P;Broussolle, E;Defebvre, L;Geny, C;Gostkowski, M;Stocchi, F;Tranchant, C;Derkinderen, P;Durif, F;Espay, AJ;Feigin, A;Houeto, J-L;Schwarz, J;Di Paolo, T;Feuerbach, D;Hockey, H-U;Jaeger, J;Jakab, A;Johns, D;Linazasoro, G;Maruff, P;Rozenberg, I;Sovago, J;Weiss, M;Gomez-Mancilla, B

Title:

A Placebo-Controlled Trial of AQW051 in Patients With Moderate to Severe LevodopaInduced Dyskinesia

Date:

2016-07-01

Citation:

Trenkwalder, C., Berg, D., Rascol, O., Eggert, K., Ceballos-Baumann, A., Corvol, J. -C., Storch, A., Zhang, L., Azulay, J. -P., Broussolle, E., Defebvre, L., Geny, C., Gostkowski, M., Stocchi, F., Tranchant, C., Derkinderen, P., Durif, F., Espay, A. J., Feigin, A. ,... GomezMancilla, B. (2016). A Placebo-Controlled Trial of AQW051 in Patients With Moderate to Severe Levodopa-Induced Dyskinesia. MOVEMENT DISORDERS, 31 (7), pp.1049-1054. https://doi.org/10.1002/mds.26569.

Persistent Link:

http://hdl.handle.net/11343/291063 